\title{
Determinants to optimize response to clopidogrel in acute coronary syndrome
}

This article was published in the following Dove Press journal:

Pharmacogenomics and Personalized Medicine

6 April 2010

Number of times this article has been viewed

\section{Betti Giusti \\ Anna Maria Gori \\ Rossella Marcucci \\ Claudia Saracini \\ Anna Vestrini \\ Rosanna Abbate}

Department of Medical and Surgical Critical Care, University of Florence, SOD Atherothrombotic Diseases, AOU Careggi, Florence, Italy
Correspondence: Betti Giusti

Department of Medical and Surgical Critical Care, University of Florence, Viale Morgagni 85, 50134 Florence, Italy

Tel +390557949420

Fax +390557949418

Email betti.giusti@unifi.it

\begin{abstract}
The inhibition of platelet function by antiplatelet therapy determines the improvement of the survival of patients with clinically evident cardiovascular disease. Clopidogrel in combination with aspirin is the recommended standard of care for reducing the occurrence of cardiovascular events in patients with acute coronary syndromes undergoing percutaneous coronary intervention. However, major adverse cardiovascular events including stent thrombosis occur in patients taking clopidogrel and aspirin. A growing body of evidence demonstrates that high post-treatment platelet reactivity on antiplatelet treatment is associated with increased risk of adverse clinical events. Clopidogrel requires conversion to active metabolite by cytochrome $\mathrm{P} 450$ isoenzymes. The active metabolite inhibits ADP-stimulated platelet activation by irreversibly binding to $\mathrm{P} 2 \mathrm{Y}_{12}$ receptors. Recently, the loss-of-function CYP2C19*2 allele has been associated with decreased metabolization of clopidogrel, poor antiaggregant effect, and increased cardiovascular events. In high risk vascular patients, the CYP2C19*2 polymorphism is a strong predictor of adverse cardiovascular events and particularly of stent thrombosis. Prospective studies evaluating if an antiplatelet treatment tailored on individual characteristics of patients, CYP2C19*2 genotypes, platelet phenotype, drug-drug interaction, as well as traditional and procedural risk factors, are now urgently needed for the identification of therapeutic strategies providing the best benefit for the single subject.
\end{abstract}

Keywords: antiplatelet therapy, clopidogrel, cytochrome P450 2C19 loss-of-function polymorphism, major adverse cardiovascular events, percutaneous coronary interventions

\section{Introduction}

Large clinical trials have shown that dual antiplatelet therapy (aspirin plus clopidogrel) reduces the risk of recurrent cardiovascular events in patients with coronary artery disease (CAD). Dual antiplatelet therapy is the standard of care for patients with acute coronary syndrome (ACS) who are managed either medically or by percutaneous coronary intervention (PCI). ${ }^{1-6}$ In particular, clopidogrel treatment has delivered substantial benefit for patients undergoing PCI and stent implantation. Patients receiving bare metal and drug-eluting stents (BMS and DES) are recommended to receive clopidogrel maintaining therapy for 1-12 months and at least 12 months, respectively. Retrospective studies have shown that the discontinuation of clopidogrel, even after 6 months or later, after stent implantation, is associated with an increased risk of thrombotic events in patients with DES. ${ }^{4-7}$ However, major adverse cardiovascular events (MACE) including stent thrombosis (ST) can also occur in patients taking clopidogrel and aspirin, and several retrospective and prospective studies ${ }^{8-18}$ have shown that patients who suffer ST have a high post-treatment platelet reactivity 
despite the dual antiplatelet treatment. This suggests that platelet aggregation nonresponsiveness to clopidogrel is the main cause of the thrombotic event. Recently, Sofi et al ${ }^{19}$ published a meta-analysis of fourteen studies (totalling 4564 CAD patients who underwent a PCI followed for a time ranging from 14 days to 1 year) demonstrating that persistent platelet reactivity, despite clopidogrel treatment, confers an increased risk of recurrent adverse cardiovascular events. Indeed, patients who were classified as clopidogrel nonresponders were at about a fivefold increased risk of nonfatal and fatal cardiovascular recurrences with respect to those classified as responders. ${ }^{19}$

Multiple potential or well-documented mechanisms involved in high on-clopidogrel platelet reactivity have been identified (Figure 1). Extrinsic or chronic mechanisms include inadequate drug compliance, ${ }^{20}$ drug-drug interactions, ${ }^{21-24}$ age, diabetes mellitus, elevated body mass index, and reduced left ventricle ejection function. ${ }^{14,20}$ Transient mechanisms include inflammation, ${ }^{25}$ accelerated platelet turnover, ${ }^{26}$ reticulated platelets, ${ }^{26,27}$ erythrocyte deformability, ${ }^{28,29}$ and ADAMTS-13 activity. ${ }^{30}$
Among the possible mechanisms, common genetic variants could play a pivotal role in determining the individual susceptibility to platelet reactivity on antiplatelet drugs. Several polymorphisms in genes coding platelet components glycoprotein (Gp)Ia, GpIIIa, GpIbalpha, GpVI, ADP-receptor P2 ${ }_{12}$ (P2Y12), P-selectin, cyclooxygenase [(COX)-1, COX-2,], endothelial nitric oxide synthase (eNOS), or cytochrome P450 (CYP450) enzyme isoforms $(-3 \mathrm{~A} 4,-3 \mathrm{~A} 5)$ have been proposed and investigated. ${ }^{31-34} \mathrm{With}$ regards to responsiveness to clopidogrel, studies in healthy subjects on clopidogrel treatment ${ }^{35,36}$ and in ACS patients undergoing PCI on dual antiplatelet treatment ${ }^{37,38}$ showed that the CYP2C19*2 allelic variant is an independent predictor of clopidogrel treatment variability.

Recently, different groups have contemporarily demonstrated, in different clinical settings and at different follow-up times, that CYP2C19*2 is a determinant of the occurrence of MACE in patients on clopidogrel therapy with an estimated risk ranging from 1.5 to $6.0 .{ }^{39-43}$ In May 2009, the US Food and Drug Administration (FDA) recommended a change to clopidogrel's prescribing label to account for
Bioavailability
Noncompliance
Underdosing
Poor absorption
Drug-drug interactions
(eg, PPIs, statins)

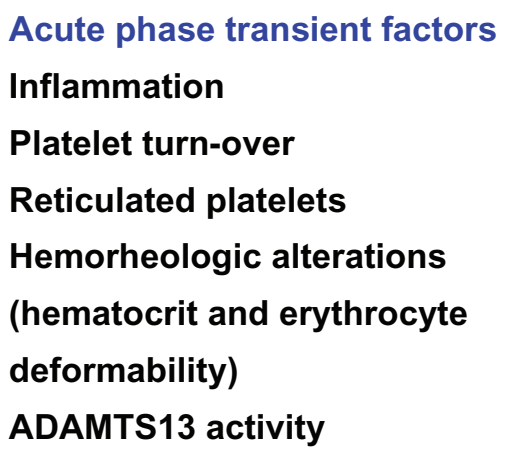

\begin{tabular}{|l|c|l|}
\hline Other factors & Residual platelet & $\begin{array}{l}\text { Platelet interaction with } \\
\text { other blood cells }\end{array}$ \\
Exercise & reactivity & $\begin{array}{l}\text { Endothelial cells and } \\
\text { Stress }\end{array}$ \\
monocytes
\end{tabular}

\section{Chronic persistent factors \\ Age \\ Diabetes \\ Systolic function \\ Hypercholesterolemia}

Single nucleotide polymorphisms

Receptors: GPIIb-IIla, GPla-Ila,

GPIbalpha, P2Y12, .....

Enzymes: COX-1, COX-2, CYP450, ...

Figure I Mechanisms of clopidogrel response variability. 
these findings (see http:// www.fda.gov/Safety/MedWatch/ SafetyInformation/ucm165166.htm).

New P2Y12 receptor antagonists are currently undergoing investigation. Prasugrel is a third generation thienopyridine that is associated with greater active metabolite generation, superior inhibition of ADP-induced platelet aggregation and less response variability than clopidogrel. ${ }^{44}$ In the Trial to Assess Improvement in Therapeutic Outcomes by Optimizing Platelet Inhibition With Prasugrel-Thrombolysis In Myocardial Infarction 38 (TRITON-TIMI 38 trial), prasugrel was compared to clopidogrel in patients with moderate to high risk ACSs undergoing PCI. ${ }^{45}$ The prevalence of cardiovascular death, nonfatal myocardial infarction, or nonfatal stroke was lower with prasugrel treatment compared to clopidogrel (12.1\% vs 9.9\%). However, a higher rate of major and minor bleeding was present in the prasugrel group. The TRITON-TIMI 38 trial conclusively demonstrated that superior P2Y12 blockade produces superior reduction in ischemic events in patients with ACS.

The novel antiplatelet agent, ticagrelor, was also evaluated against clopidogrel in the PLATO (A Study of Platelet Inhibition and Patient Outcomes) trial of patients with ACS. When compared with clopidogrel, ticagrelor was associated with a significant reduction in mortality in this population, without increasing the overall incidence of major bleeding. ${ }^{46}$ Moreover, other antiaggregant drugs such as prostaglandin analogues (iloprost), a PDE3 phosphodiesterase inhibitor (cilostazol), and a further short-acting competitive $\mathrm{P} 2 \mathrm{Y} 12$ platelet receptor antagonist (cangrelor) are available and might be considered in the management of high risk vascular patients.

The issue of the monitoring of clopidogrel therapy and/or the personalization of alternative antiplatelet therapeutic strategies aimed to reduce ischemic events without increasing the bleeding risk is unresolved. Clinicians are interested in the evaluation of how the entity of platelet function inhibition, induced by antiplatelet drugs, affects the risk of recurrent ischemic events. Therefore, we believe it is crucial to define the concept of "residual platelet reactivity" (RPR) on antiplatelet treatment and identify its determinants. The optimal level of platelet inhibition to prevent cardiovascular events is modulated by clinical characteristics and, at present, there is no platelet function cut-off which is widely accepted to identify patients at high risk for ischemic events in different clinical settings. Ongoing clinical trials are evaluating if an antiplatelet treatment tailored on the entity of platelet inhibition is a good strategy in terms of safety and efficacy. On the other hand, based on more recent findings, further studies are desirable to evaluate tailored treatment on the entity of platelet inhibition as well as other genetic, procedural and environmental factors. These studies could offer crucial feedback on the utility of monitoring antiplatelet therapies and other risk factors of hyper-aggregability in order to prevent clinical events.

\section{Clopidogrel metabolism}

Different agonists are known to induce platelet aggregation and fibrinogen binding to the subsequently activated integrin GPIIb-IIIa complex. In this process, ADP is of particular importance, because it is released by damaged cells and activated platelets, thus enhancing the action of many platelet activators. ${ }^{47}$ ADP mediates platelet aggregation by binding to two $G$ protein-coupled receptors (GPCRs), $\mathrm{P}_{2} \mathrm{Y}_{1}$ and $\mathrm{P} 2 \mathrm{Y}_{12}$, acting together to achieve complete aggregation. ${ }^{48}$ $\mathrm{P} 2 \mathrm{Y}_{12}$ also has an important role in amplifying the responses to other agonists. In fact, ADP is released from plateletdense granules regardless of the activating stimulus, be it thrombin, collagen, thromboxane $\mathrm{A}_{2}$, or other agonists. Therefore, $\mathrm{P} 2 \mathrm{Y}_{12}$ has a major role in arterial thrombosis and the concomitant inflammatory response, and pharmacological targeting of this receptor has become an important strategy in cardiovascular disease research.

Clopidogrel, a P2Y ${ }_{12}$ ADP-receptor antagonist, belongs to the thienopyridine class of chemical compounds, and it is a pro-drug requiring oxidation by the hepatic CYP450 to generate an active thiol metabolite (SR26334) (Figure 2). ${ }^{49,50}$ Clopidogrel is absorbed in the duodenum. The P-glycoprotein coded by the ABCB1 gene is responsible for the active intestinal transport of clopidogrel (Figure 2). Only about $15 \%$ of clopidogrel undergoes metabolism by CYP450. It is mostly hydrolyzed by esterases to an inactive carboxylic acid derivative that accounts for $85 \%$ of clopidogrel-related circulating compounds (Figure 2). Several CYP450 enzyme isoforms (ie, CYP1A2, CYP2B6, and CYP2C19) are responsible for the oxidation of the thiophene ring of clopidogrel to 2-oxoclopidogrel, which is further oxidized by CYP2B6, CYP2C9, CYP2C19, and CYP3A4, resulting in the opening of the thiophene ring and the formation of both a carboxyl and a thiol group (Figure 2) ${ }^{49}$ The latter forms a disulphide bridge with the two extracellular cysteine residues located on the ADP P2 $Y_{12}$ receptor expressed on the platelet surface, and causes an irreversible blockade of ADP-binding for the platelet's life span. ${ }^{51}$ The contribution of CYP1A2, CYP2B6, and CYP2C19 to the formation of 2-oxo-clopidogrel was 35.8, 19.4 and 44.9\%, respectively (Figure 2). ${ }^{52}$ The contribution of CYP2B6, CYP2C9, CYP2C19, and CYP3A4 to the formation of the active metabolite was $32.9,6.76,20.6$, and $39.8 \%$, respectively (Figure 2 ). ${ }^{52}$ These data showed that 


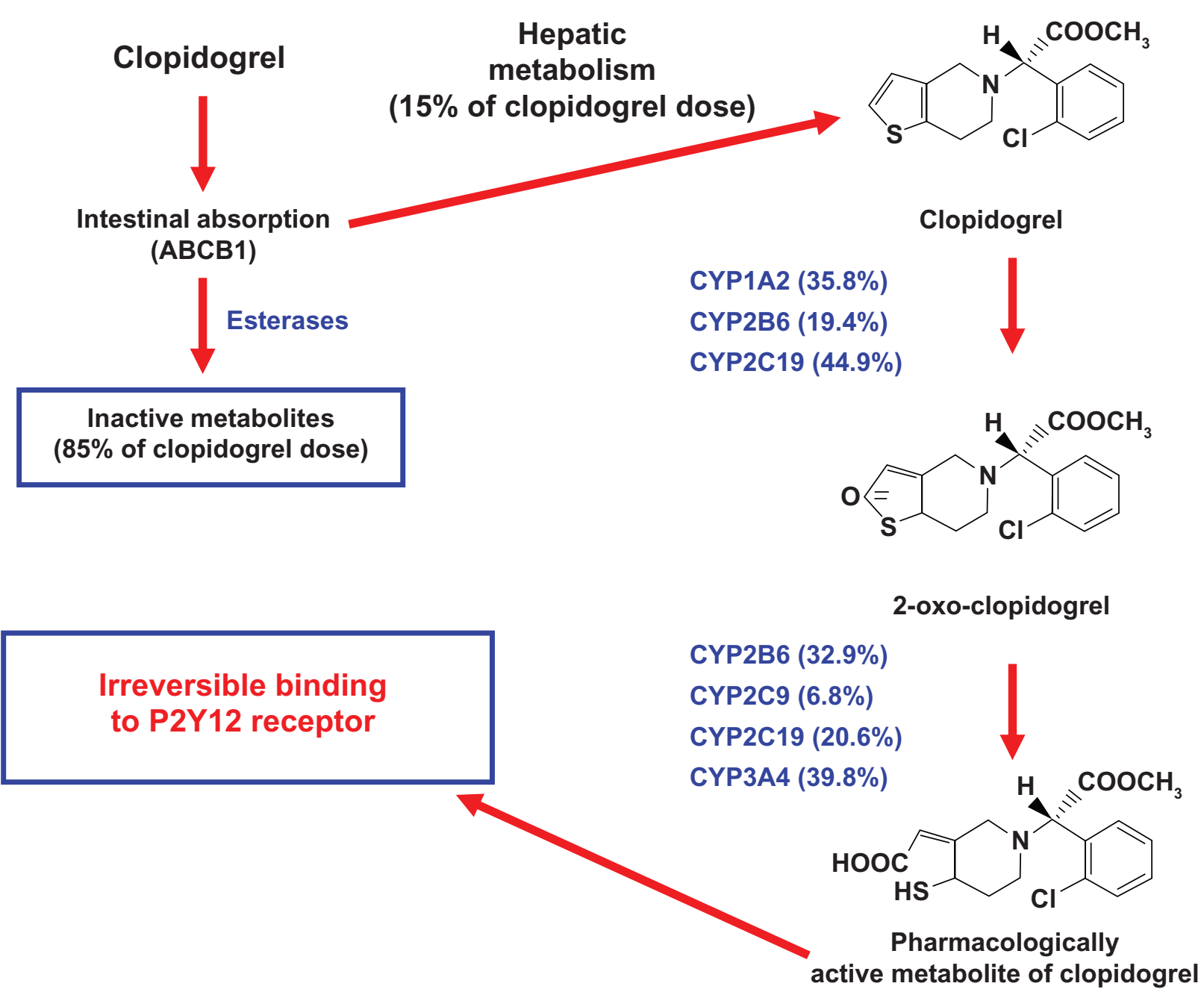

Figure 2 Mechanism of action of clopidogrel.

Abbreviations: ABCBI, ATP-binding cassette, sub-family B; MDR/TAP, member I gene coding for the P-glycoprotein involved in the clopidogrel intestinal absorption; CYPIA2 is cytochrome P450, family I, subfamily A, polypeptide 2; CYP2B6, cytochrome P450, family 2, subfamily B, polypeptide 6; CYP2C19, cytochrome P450, family 2, subfamily C, polypeptide 19; CYP2C9, cytochrome P450, family 2, subfamily C, polypeptide 9; CYP3A4, cytochrome P450, family 3, subfamily A, polypeptide 4; P2Y I2, purinergic receptor P2Y, G-protein coupled, 12.

CYP2C19 contributed substantially to both oxidative steps required in the formation of clopidogrel active metabolite, and they help to explain the role of genetic polymorphism of CYP2C19. Indeed, among the different CYP450 isoenzymes involved in clopidogrel metabolism, a single nucleotide polymorphism (SNP; CYP2C19*2) has been associated with inactivation of the enzyme and impaired metabolism of drugs, including clopidogrel, via this pathway. The CYP2C19 enzyme is responsible for the metabolism and clearance of numerous drug substrates including proton pump inhibitors (PPIs), diazepam, phenytoin, and cyclophosphamide.

\section{Definition of high on-clopidogrel platelet reactivity}

Laboratory methods used to evaluate platelet function included light transmission aggregometry on platelet-rich plasma
(PRP LTA), flow cytometry, the Ultegra Rapid PlateletFunction Assay-VerifyNow ${ }^{\circledR}$, and whole blood aggregometry by Multiplate system. The gold standard for evaluating platelet function is LTA induced by adenosine-diphosphate (ADP). However, aggregometry is time-consuming and requires a specialized laboratory. Flow cytometry by use of the vasodilator-stimulator phosphoprotein (VASP) assay detects the availability of the P2Y12 receptor and determines the effectiveness of clopidogrel. The point-of-care tests are less laborious and more time-efficient. The PFA-100 uses cartridges with epinephrine or ADP to mimic a high-shear state to evaluate platelet function. The VerifyNow ${ }^{\circledR}$ assay system is a turbidimetry-based optical device that measures platelet aggregation. Paniccia et al compared the VerifyNow ${ }^{\circledR}$ P2Y12, PFA-100, VASP, and LTA and found a significant correlation between LTA, VASP and VerifyNow ${ }^{\circledR}$. 53,54 
In 2007 , the first meta-analysis was published examining the data present in the literature, calculating the risk associated with a RPR on clopidogrel as an odds ratio $(\mathrm{OR})=8.0(95 \%$ [confidence interval] CI: 3.4-19.1) on a total of 1025 patients undergoing PCI with stenting. ${ }^{55}$ The significant heterogeneity is a limit of this analysis, which reflects the variability in the methods and patients presented in the published papers. Since this meta-analysis, several studies have been published confirming the association between RPR on clopidogrel and the enhanced risk of adverse clinical events. In particular, data from the Low Responsiveness to Clopidogrel and Sirolimus- or Paclitaxel-Eluting Stent Thrombosis (RECLOSE) ${ }^{14}$ trial showed that a reduced response to clopidogrel (measured by LTA induced by $10 \mu \mathrm{M}$ ADP) was an independent predictor of ST and cardiovascular death in 804 patients undergoing PCI with implantation of a DES. From a subsequent analysis of the same cohort of patients, Gori et al found that the contemporary reduced response to both aspirin (measured by LTA induced by arachidonic acid) and clopidogrel is the most important predictor of the same end-points (ST and cardiovascular death). ${ }^{15}$ This result emphasizes that 'global' platelet hypereactivity identifies vulnerable patients at higher risk of recurrences.

Furthermore, a great amount of attention has been focused on the clinical validation of the point-of-care tests. Price et a ${ }^{16}$ showed, on 380 patients undergoing PCI with stent implantation, that RPR on clopidogrel measured by VerifyNow ${ }^{\circledR} \mathrm{P} 2 \mathrm{Y} 12$ is associated with a significantly higher risk of adverse clinical events at a 6-month follow up. A study entitled Antiplatelet therapy for reduction of Myocardial Damage during Angioplasty-Platelet Ractivity Predicts Outcome (ARMYDA-PRO) ${ }^{56}$ reported a significant association between RPR (measured by VerifyNow ${ }^{\mathbb{R}}$ P2Y12) and 30-days MACE on 160 patients undergoing PCI. Finally, Marcucci et al demonstrated, with a larger sample (683 ACS patients), that RPR measured by VerifyNow ${ }^{\circledR}$ P2Y12 is associated with a higher risk of cardiovascular death and nonfatal myocardial infarction at a 12-month follow up. ${ }^{17}$ Recently, Sofi et a ${ }^{19}$ performed an updated meta-analysis on clinical consequences of clopidogrel nonresponsiveness among over 4500 patients followed for a period ranging from 2 weeks to 1 year after a PCI. This meta-analysis indicated that poor responders to clopidogrel, however defined, are at increased risk of cardiovascular clinical recurrences as compared to those with a good response to the antiplatelet therapy (OR 5.67, 95\% CI: $2.97-10.84 ; P<0.00001) .{ }^{19}$

\section{Management of antiplatelet drug resistance}

There is, at present, little evidence to guide treatment of high risk vascular patients with laboratory evidence of a RPR to clopidogrel. Empirical strategies include increasing the dose of the antiplatelet agents (aspirin and clopidogrel) or adding a third antiplatelet drug.

Different trials have also shown a higher platelet inhibition with increased dosage of clopidogrel, combining synergistic medications and evaluating medications that potentially hinder the $\mathrm{P} 450$ conversion of clopidogrel into its active form. Gurbel et al showed that a loading dose of $600 \mathrm{mg}$ of clopidogrel decreased platelet reactivity compared to a loading dose of $300 \mathrm{mg} .{ }^{57} \mathrm{In}$ a similar trial, von Beckerath evaluated different doses of clopidogrel in 60 patients who had ischemic heart disease and were undergoing elective PCI and found that a $600 \mathrm{mg}$ loading dose of clopidogrel increased platelet inhibition over a $300 \mathrm{mg}$ loading dose ${ }^{58}$ Loading doses greater than $600 \mathrm{mg}$ of clopidogrel did not increase platelet inhibition, most likely due to limited absorption.

In the Optimizing Antiplatelet Therapy in Diabetes Mellitus (OPTIMUS) study, ${ }^{59}$ Angiolillo et al evaluated patients with type 2 diabetes mellitus and CAD and found that a $150 \mathrm{mg}$ dose of clopidogrel was associated with a reduced platelet inhibition in patients with a RPR on standard therapy. None of these studies reported a significantly higher bleeding rate in patients on higher clopidogrel doses. Lau showed that clopidogrel given with rifampin, a cytochrome P450 P3A4 inducer, converted nonresponders to responders. ${ }^{60}$

Ongoing trials, (Gauging Responsiveness with A VerifyNow $^{\circledR}$ assay-Impact on Thrombosis And Safety [GRAVITAS]; Double Randomization of a Monitoring Adjusted Antiplatelet Treatment versus a Common Antiplatelet Treatment for DES Implantation and Interruption Versus Continuation of Double Antiplatelet Therapy [ARCTIC)]; and Dual ANtiplatelet Tailored therapy based on the Extent of platelet inhibition [DANTE]), will establish whether an increase in the clopidogrel maintenance dose (150 mg vs $75 \mathrm{mg}$ daily) is necessary in patients with RPR on clopidogrel, specifically if a treatment tailored on the extent of platelet inhibition is associated with a reduced number of recurrences.

Furthermore, new antiplatelet agents are in the most advanced phases of clinical evaluation to become available in clinical practice for acute treatment of atherothrombotic events and/or secondary prophylaxis. These include prasugrel (currently licensed) and ticagrelor, cangrelor, and terutroban (under clinical evaluation). 
Results of ongoing or prospective studies are urgently needed to evaluate more effective and safe therapeutic strategies in these high risk vascular patients.

\section{Nonpharmacogenetic factors influencing response to clopidogrel}

Multiple factors have been proposed to explain individual variability of response to antiplatelet drugs defined as high onclopidogrel platelet reactivity (Figure 1). Clopidogrel noncompliance may represent a critical issue. In fact, discontinuation of clopidogrel therapy was found in about $15 \%$ (within 30 days) of patients with $\mathrm{CAD}^{61}{ }^{61}$ in $18.4 \%$ (at 3 months), and up to $38.4 \%$ (at 1 year) in a cohort of patients after stroke. ${ }^{62}$ It also represents an independent predictor of $\mathrm{ST}^{63}$ Recently, in $\mathrm{CAD}(\mathrm{N}=422)$ and in post-ischemic stroke $(\mathrm{N}=209)$ patients, Serebruany et $\mathrm{l}^{64}$ showed that clopidogrel therapy is associated with double-digit underestimated risks for noncompliance, especially in stroke survivors. Their data support the hypothesis that lack of inhibition of platelet aggregation (IPA), and clopidogrel "resistance" are attributed to hidden noncompliance. Even if it would not apply to or represent a minor issue in the short-term studies, noncompliance may have a significant impact on the longer range studies. In fact, they proposed that plasma inactive carboxyl metabolite, but not unchanged clopidogrel, or active thiol metabolite, is a useful marker to monitor compliance to clopidogrel in registries and clinical trials. ${ }^{64}$

Concurrent medication use may interfere with the ability of clopidogrel to decrease platelet reactivity. Gurbel and colleagues reported that high doses of calcium-channel blockers and angiotensin-converting enzyme inhibitors could possibly contribute to a decreased response to clopidogrel. ${ }^{20}$ Atorvastatin is the most frequently studied lipophilic statin in clopidogrel trials as it has a high affinity for CYP3A4. Studies that have evaluated clopidogrel resistance and atorvastatin have not been uniformly reproducible. Lau et al showed that atorvastatin promoted clopidogrel resistance at 10, 20, and $40 \mathrm{mg}$ doses..$^{65}$ On the contrary, pravastatin, which has a nonhepatic metabolism, was found to not significantly affect platelet inhibition by clopidogrel. Subsequent studies, however, did not confirm this interaction. Post-hoc analysis of several important trials (eg, Clopidogrel for the Reduction of Events During Observation [CREDO], Plavix Reduction Of New Thrombus Occurrence [PRONTO], Maximal Individual Therapy in Acute Myocardial Infarction Plus [MITRA PLUS] has not revealed a significant interaction between statins (ie, atorvastatin, fluvastatin, lovastatin, pravastatin, simvastatin) and clopidogrel in terms of entity of platelet inhibition. ${ }^{66,67}$

A growing body of evidence has been recently accumulated highlighting the interaction between proton pump inhibitors (PPIs) and clopidogrel when influencing platelet reactivity. ${ }^{21-23,68,69}$ Approximately $15 \%$ of an absorbed clopidogrel dose is converted to an active thiol metabolite, mainly by the hepatic CYP450 isoenzymes. ${ }^{50}$ One of these isoenzymes, the CYP2C19 isoform, is involved in the metabolism of many of the PPIs, which are also inhibitors of the CYP2C19 isoenzyme to varying degrees. ${ }^{70}$ The capability of PPI to inhibit CYP2C19 activity would reduce the active metabolite of clopidogrel generation and cause a diminished platelet response to clopidogrel. In addition to this mechanism, PPIs may influence the antiplatelet clopidogrel response via the variability of intestinal absorption of clopidogrel. ${ }^{71,72}$ PPIs are substrates and inhibitors of the intestinal efflux transporter P-glycoprotein, a key factor for intestinal absorption of clopidogrel..$^{70}$ Alterations in P-glycoprotein activity could potentially affect plasma concentrations of clopidogrel and hence the concentration of active metabolite. Gilard et al documented, for the first time, that the contemporary administration of clopidogrel and omeprazol is associated with a reduced platelet inhibition related to P2Y12 receptors in 105 CAD patients. ${ }^{73}$ In the Omeprazole CLopidogrel Aspirin (OCLA) study trial, ${ }^{68}$ 140 CAD patients undergoing stent implantation on dual antiplatelet treatment were randomized to receive $20 \mathrm{~g}$ /day of omeprazole or a placebo for 7 days. This treatment significantly decreased the effect of clopidogrel on platelet reactivity as tested by platelet vasodilator-stimulated phosphoprotein (VASP) phosphorylation assay. ${ }^{68}$

The influence of pantoprazole and esomeprazole on the clopidogrel antiplatelet response was investigated in two different studies evaluating 300 and 100 patients undergoing PCI respectively. ${ }^{23,69}$ In these ex vivo studies, the intake of pantoprazole or esomeprazole was not able to impair the platelet inhibition by clopidogrel. A recent ex vivo study has evaluated the effect of pantoprazole and omeprazole on inhibition by clopidogrel in 104 nonST-segment elevation (NSTE) ACS patients and found, after 1 month of treatment, a significantly reduced platelet inhibition by omeprazole, but not by pantoprazole. ${ }^{74}$ Contrasting data about the capability of PPI administration to influence the risk of clinical events are available. In 13636 patients with acute myocardial infarction (AMI) treated with clopidogrel, the use of PPIs was associated with an increased risk of AMI. ${ }^{21}$ However, the use of pantoprazole 
did not significantly affect the risk of AMI, whereas the other PPIs were associated with an increased risk of about $40 \%$. In a retrospective study of 8205 patients with ACS, the use of clopidogrel plus PPIs (at discharge, during follow-up or both) was associated with an increased risk of death or rehospitalization for ACS compared with the use of clopidogrel without PPIs. By analyzing the different PPIs in relation to adverse outcomes, the above mentioned study failed to demonstrate a significant difference between omeprazole and raboprazole. ${ }^{24}$ Recently, the authors of PRINCIPLE (Prasugrel in comparison to Clopidogrel for inhibition of Platelet Activation and Aggregation)-TIMI 44 and TRITON-TIMI 38 trials, retrospectively analyzed data in order to verify the possible interactions between the use of PPIs, platelet function, and adverse cardiovascular events in relation to both clopidogrel and prasugrel. In both trials, the use of PPIs was not significantly associated with an increased risk of ischemic events either in patients treated with clopidogrel or prasugrel. This was confirmed at the subgroup analysis with single PPIs (omeprazole, pantoprazole, esomeprazole, and lansoprazole) both in patients treated with clopidogrel or prasugrel. ${ }^{22}$

Taubert et $\mathrm{al}^{75}$ demonstrated that intestinal absorption is the main factor determining the production of active metabolites of clopidogrel. Paralleling these results, are those reported in Intracoronary Stenting and Antithrombotic Regimen: Choose Between 3 High Oral Doses for Immediate Clopidogrel Effect (ISAR-CHOICE). This study demonstrated that by comparing the effects of clopidogrel on the inhibition of platelet function at higher loading doses (300, $600,900 \mathrm{mg}$ ) there are no advantages in dosing higher than $600 \mathrm{mg}$, as this does not result in a corresponding higher level of active metabolite in plasma. ${ }^{58}$ This datum suggests that intestinal absorption is reduced for doses higher than $600 \mathrm{mg}$.

The available evidence indicates that advanced age is associated with a significantly high percentage of patients with high on-clopidogrel platelet reactivity. One of the possible causes is related to the fact that the conversion of clopidogrel to its active metabolite may be impaired in older patients. ${ }^{76,77}$ In a recent prospective study ${ }^{78}$ evaluating 191 patients who had undergone PCI, ADP-inducible platelet reactivity increased linearly with age after adjustment for cardiovascular risk factors, type of intervention, medication, C-reactive protein, and renal function. By contrast, the study by Price et $\mathrm{al}^{79}$ which evaluated various factors that may affect ADP-inducible platelet reactivity in patients on continuous clopidogrel therapy, demonstrated no effect due to age $\geq 75$ years. ${ }^{79}$ This discrepancy may be attributed to the duration of clopidogrel therapy. Most of patients of the Gremmel study received a loading dose of clopidogrel prior to angioplasty, while the Price study assessed platelet aggregation mainly in patients on continuous clopidogrel therapy. ${ }^{78,79}$ Therefore, the attenuation of clopidogrelmediated platelet inhibition at an advanced age may be a phenomenon of the initial phase of antiplatelet therapy.

Diabetes mellitus is a clinical condition which is characterized by enhanced platelet reactivity which exposes diabetic patients to an increased risk of atherothrombotic events. In fact, platelets in diabetics respond more frequently even to subthreshold stimuli, are consumed more rapidly, and thus contribute to accelerated thrombopoiesis compared to platelets in nondiabetic individuals. ${ }^{80}$ It has been documented that high on-clopidogrel platelet reactivity is more prevalent in diabetic than nondiabetic patients. ${ }^{81-83}$ In particular, type 2 diabetic patients undergoing elective PCI have approximately a fourfold increase in the number of nonresponders at 24 hours following a standard $300 \mathrm{mg}$ loading dose. Moreover, platelet reactivity is persistently elevated in diabetic patients even in the maintenance phase of clopidogrel and is highest among those patients requiring insulin therapy. ${ }^{81}$

Recent studies have documented a significant and independent association between platelet hyper-reactivity and both routinary inflammatory markers (eg, erythrocyte sedimentation rate and leukocyte number), ${ }^{84}$ and unbalanced proinflammatory/anti-inflammatory cytokine levels. This suggests that a proinflammatory state, not sufficiently compensated by anti-inflammatory cytokines, modulates platelet hyperreactivity during the acute phase of the disease in patients on dual antiplatelet treatment. ${ }^{25}$ Recently, it was observed that patients treated with long-term clopidogrel and aspirin therapy who underwent elective PCI had less inflammation, indicated by specific biomarkers (ie, $\mathrm{C}$ reactive protein and other proinflammatory cytokines), compared with clopidogrel-naïve patients. This datum suggests that long-term clopidogrel therapy is associated with an anti-inflammatory effect. ${ }^{85}$

An elevated turnover of the circulating platelet pool yields a larger population of young platelets which are more reactive than an older population of platelets. The younger platelets have increased mean volume and a greater number of dense granules than older circulating platelets. ${ }^{86}$ In both healthy subjects and in patients with stable CAD, it has been demonstrated that an increased platelet turnover, as reported by the proportion of circulating reticulated platelets (RPs), 
exhibits significantly increased aggregation and activation responses even after dual antiplatelet therapy. ${ }^{27,86-88}$ Moreover, in 372 ACS patients on dual antiplatelet therapy, the number of patients with suboptimal or "low response" to aspirin, clopidogrel or both was clustered among patients with a high proportion of circulating RPs. ${ }^{26}$

The adhesion and activation of platelet at sites of vascular injury is mediated by von Willebrand factor (VWF). VWF, which is released from storage sites or secreted by endothelial cells as ultra large VWF (ULVWF), is rapidly cleaved through intravascular proteolysis by ADAMTS-13. ${ }^{89}$ In the acute phase of CAD and after the vascular injury induced by a PCI, endothelial cells are activated and high amounts of ULVWF are released. ${ }^{90}$ ULVWF forms are able to bind the glycoprotein 1b-IX complex and aggregate platelets. ${ }^{91}$ In physiological conditions, the large multimeric forms are rapidly cleaved by the ADAMTS-13 on the surface of the endothelium, resulting in the generation of the normal multimeric pattern of VWF. ${ }^{89,92}$ When ADAMTS-13 activity is reduced, the ULVWFs accumulate and can induce platelet aggregation. ${ }^{89}$ High on-clopidogrel platelet reactivity is associated with lower ADAMTS-13 activity accompanied by elevated VWF levels, ${ }^{30}$ suggesting a modulatory effect of the interplay between ADAMTS-13 and VWF on the response to antiplatelet therapy in patients with a marked endothelial activation, such as those with ACS who have undergone PCI.

Red blood cells and leukocytes are significantly implicated into the pathogenesis of arterial thrombosis. Platelet-leukocyte interactions play an important role in both adhesion and activation of platelets, but red blood cells are also involved in the interactions between platelets and the vessel wall. In patients with ACS, the inhibition of platelets induced by aspirin is modulated not only by the direct action on platelets, but also by the erythrocyte deformability and the white blood cell count. ${ }^{28}$ This suggests that all blood components, including red blood cells, should be taken into account. Some hemorheologic variables are also associated with high on-treatment platelet reactivity in patients with ACS on dual antiplatelet therapy. In particular, decreased erythrocyte deformability is significantly associated with increased platelet aggregation induced by ADP. ${ }^{29}$ A possible explanation for this association is that erythrocytes with decreased deformability tend to release a larger amount of ADP in the circulation compared to those without ${ }^{93}$ and this released ADP can compete with clopidogrel for purinergic receptors present on the platelet surface.

\section{Association of cytochrome P450 2CI 9 loss-of-function polymorphism with high on-clopidogrel platelet reactivity}

Several polymorphisms in different genes coding isoforms of CYP450 have been investigated as possible determinants of the high on-clopidogrel platelet reactivity (ie, genetic variants in CYP3A4, CYP3A5, CYP1A2, CYP2B6, CYP2C9, CYP2C19, ABCB1 genes). For the majority of the investigated polymorphisms, results are negative or inconsistent, however, consistent data are available concerning a polymorphism in the gene CYP2C19 on chromosome 10. Several CYP2C19 variant alleles have been identified and exhibit functional impairment which phenotypically categorized subjects as poor metabolizers. The CYP2C19*2 loss-of-function polymorphism is a G681A nucleotide substitution at the junction of intron 4 and exon 5, which introduces a splicing defect resulting in a truncated, nonfunctional protein, responsible for the poor-metabolizer phenotype. ${ }^{94}$ The CYP2C19*2 variant allele has different minor allele frequencies in Caucasian (15\%), Asian (30\%), and African American (17\%) populations. ${ }^{95}$ The CYP2C19*3 variant allele is a G636A nucleotide substitution in exon 4 , which creates a premature stop codon at aminoacid position 212 resulting in a truncated, metabolically inactive, protein and poor-metabolizer phenotype. ${ }^{94}$ The CYP2C $19 * 3$ polymorphism is found infrequently in the Asian population $(5 \%)$ and is rare in both Caucasian $(0.04 \%)$ and African American $(0.4 \%)$ populations..$^{95}$ Other rare variant alleles contribute to determine the poor-metabolizer phenotype, such as CYP2C19*4 and CYP2C19*5.

\section{Studies in healthy subjects}

Different studies have evaluated the impact of CYP2C19*2 polymorphism on clopidogrel pharmacokinetics and pharmacodynamics in healthy volunteers (Table 1 ). Hulot et $a^{35}$ first demonstrated that the CYP2C19 loss-of-function allele is associated with a marked decrease in platelet responsiveness to clopidogrel in 28 young, healthy male volunteers treated for 7 days with clopidogrel at $75 \mathrm{mg} / \mathrm{d}$. Fontana et $\mathrm{a}^{96}$ replicated the evidence for the association between CYP2C $19 * 2$ allele and impaired clopidogrel responsiveness in 94 healthy subjects by assessing the ADP-induced platelet aggregation after a 1-week course of clopidogrel (300 mg the first day and $75 \mathrm{mg} /$ day thereafter) and showed that the polymorphism explained $10 \%$ of the variability of clopidogrel responsiveness when the analysis was adjusted for age, 
Table I Association of CYP2C19*2 loss-of-function polymorphism with response variability to clopidogrel treatment in healthy subjects

\begin{tabular}{|c|c|c|c|c|c|}
\hline Study & $\mathbf{N}$ subjects & Treatment & Functional evaluation & $\begin{array}{l}\text { CYP2CI 9*2 } \\
\text { carriers \% }\end{array}$ & Association \\
\hline Hulot et a $\left.\right|^{35}$ & 28 Caucasian males & $75 \mathrm{mg} /$ day for 7 days & $10 \mu \mathrm{MADP}$-induced PA & 28.6 & Yes \\
\hline Fontana et $\mathrm{al}^{96}$ & 94 Caucasians & $\begin{array}{l}300 \mathrm{mg} \text { the first day then } \\
75 \mathrm{mg}_{\text {day }}{ }^{-1} \text { for } 7 \text { days }\end{array}$ & $20 \mu \mathrm{M}$ ADP-induced PA & 27.7 & Yes \\
\hline Brandt et $\mathrm{al}^{36}$ & $\begin{array}{l}74 \text { Caucasians } \\
\text { (57 male/l } 7 \text { female) }\end{array}$ & $300 \mathrm{mg}$ & $\begin{array}{l}20 \mu M \text { ADP-induced PA } \\
\text { Active metabolite by LC }+ \text { MS }\end{array}$ & 25.8 & Yes \\
\hline Kim et al ${ }^{97}$ & 24 Koreans & $\begin{array}{l}300 \mathrm{mg} \text { the first day then } \\
75 \mathrm{mg}_{\text {day }}{ }^{-1} \text { for } 7 \text { days }\end{array}$ & $\begin{array}{l}5 \mu M \text { ADP-induced PA } \\
\text { PCC by LC }+ \text { MS }\end{array}$ & 66.6 (selected) & Yes \\
\hline Umemura et al ${ }^{98}$ & 47 Japanese & $300 \mathrm{mg}$ & $\begin{array}{l}20 \mu M \text { ADP-induced PAVASP ph } \\
\text { Active metabolite by LC + MS }\end{array}$ & 61.7 & Yes \\
\hline Mega et a $\left.\right|^{40}$ & 162 (I30 male/32 female) & $\begin{array}{l}300-600 \mathrm{mg} \pm 75 \mathrm{mg} / \text { day } \\
\text { for } 7 \text { days }\end{array}$ & $\begin{array}{l}20 \mu \mathrm{M} \text { ADP-induced PA } \\
\text { Active metabolite by LC }+ \text { MS }\end{array}$ & 34.0 & Yes \\
\hline
\end{tabular}

Abbreviations: N, number; PA, platelet aggregation; LC + MS, liquid chromatography with tandem mass spectrometry; PCC, plasma concentrations of clopidogrel; VASPph, vasodilator-stimulated phosphoprotein phosphorylation.

platelet count, hematocrit, collagen lag time, fibrinogen, and von Willebrand levels.

In order to determine the relationship between genetic variants in CYP450 isoenzymes and response to prasugrel and clopidogrel, Brandt et $\mathrm{al}^{36}$ genotyped for CYP1A2, CYP2B6, CYP2C19, CYP2C9, CYP3A4 and CYP3A5 genetic variants in healthy subjects participating in studies evaluating pharmacokinetic and pharmacodynamic response to prasugrel $(60 \mathrm{mg}, \mathrm{N}=71)$ or clopidogrel $(300 \mathrm{mg}$, $\mathrm{N}=74$ ). In subjects treated with clopidogrel, the presence of the CYP2C19*2 polymorphism was significantly associated with lower exposure to clopidogrel active metabolite, lower inhibition of platelet aggregation at 4 hours, and poor responder status. Likewise, CYP2C9 loss-of-function variants (polymorphisms in another gene coding a different CYP450 isoenzyme) were significantly associated with lower exposure to clopidogrel active metabolite, lower inhibition of platelet aggregation at 4 hours, and poor responder status. Concerning prasugrel, there was no significant relationship between CYP2C19 or CYP2C9 polymorphisms and exposure to the active metabolite of prasugrel or pharmacodynamic response.

Recently, in a study of 162 healthy subjects on $300 \mathrm{mg}$ dose of clopidogrel, Mega et a ${ }^{40}$ confirmed that carriers of at least one CYP2C19 reduced-function allele (30\% of the study population) had a relative reduction of $32.4 \%$ in plasma exposure to the active metabolite of clopidogrel, as compared with noncarriers. Carriers also had an absolute reduction in maximal platelet aggregation in response to clopidogrel that was $9 \%$ less than that observed in noncarriers.
Kim et al ${ }^{197}$ divided 24 Korean subjects into three groups on the basis of their CYP2C19 genotype: homozygous extensive metabolizers (homo-EMs, $\mathrm{N}=8$ ), heterozygous EMs (hetero-EMs, $\mathrm{N}=8$ ), and poor metabolizers ( $\mathrm{PMs}, \mathrm{N}=8$ ). After a single $300 \mathrm{mg}$ loading dose of clopidogrel on day 1, followed by a $75 \mathrm{mg}$ daily maintenance dose from days 2 to 7 , they measured the plasma levels of clopidogrel and assessed the antiplatelet effect as pharmacodynamic. The mean clopidogrel area under the curve (AUC) for PMs was 1.8- and 2.9-fold higher than that for hetero-EMs and homoEMs, respectively. The mean peak plasma concentration in PMs was 1.8- and 4.7-fold higher than that of hetero-EMs and homo-EMs, respectively. PMs exhibited a significantly lower antiplatelet effect than hetero-EMs or homo-EMs.

In their study of 47 healthy Japanese subjects, Umemura et $\mathrm{a}^{98}$ determined plasma concentrations of the active metabolite before and at $0.25,0.5,1,2,4$, and $8 \mathrm{~h}$ after treatment with $300 \mathrm{mg}$ clopidogrel. Also, before and at 1, 4, 6, and $24 \mathrm{~h}$ after treatment, they measured inhibition of platelet aggregation to ADP and VASP. They confirmed that the CYP2C19*2 polymorphism is a determinant for the formation of the active metabolite and demonstrated that the pharmacokinetic parameters, area under the plasma concentration-time curves, and peak concentration $\left(\mathrm{C}_{\max }\right)$ of the active metabolite were well correlated with the platelet reactivity index by VASP, and inhibition of platelet aggregation to ADP. Their findings suggest that low or no responsiveness to clopidogrel is mainly caused by the lower metabolic formation of the metabolite, but not because of the poor sensitivity of the platelet P2Y12 receptor. 
Recently, in the Pharmacogenomics of Antiplatelet Intervention (PAPI) Study, Shuldiner et al ${ }^{99}$ administered clopidogrel (300 mg oral loading dose followed by $75 \mathrm{mg} / \mathrm{d}$ for 7 days) to 429 healthy Amish persons and measured response by ex vivo platelet aggregometry (ie, baseline platelet aggregation and 1 hour following the last dose of clopidogrel). In this population, they performed a genome-wide association study followed by genotyping the CYP2C19*2 polymorphism. The presence of relatives in the population allowed them to observe that platelet response to clopidogrel was highly heritable $\left(\mathrm{h}^{2}=0.73 ; P<0.001\right)$. They identified 13 polymorphisms on chromosome 10q24 within the CYP2C18-CYP2C19-CYP2C9-CYP2C8 cluster associated with diminished clopidogrel response. All these polymorphisms were in strong linkage disequilibrium with the rs12777823, the most significantly associated polymorphism $\left(P=1.5 \times 10^{-13}\right.$ for the additive model). The rs12777823 polymorphism was in strong linkage disequilibrium with the CYP2C19*2 variant accounting for the $12 \%$ of the variation in platelet aggregation to $\mathrm{ADP}\left(P=4.3 \times 10^{-11}\right)$. No other genomic region revealed association signals that met or exceeded genome-wide significance $\left(P<1.0 \times 10^{-7}\right)$. These data suggest that, in this population of healthy subjects, the common loss-of-function CYP2C19*2 variant could account for most of the association signal detected in the genome-wide association study. Due to the high heritability of the platelet response to clopidogrel, other common SNPs not present on the chip, or other types of variants (eg, copy number variations, insertions/deletions), or rare variants with large effect size not tagged by those SNPs genotyped might play an important role.

\section{Studies in high risk vascular patients}

In 2007, Giusti et al ${ }^{37}$ first studied the effect of CYP2C $19 * 2$ loss-of-function polymorphism in modulating platelet function in ACS patients on dual antiplatelet treatment who had undergone PCI (Table 2). In that paper, for the first time, the finding that the $* 2$ allele of the CYP2C19 gene was associated with higher platelet aggregability and RPR in 1419 high risk vascular patients on dual antiplatelet treatment was reported. Carriers of the CYP2C19*2 rare allele of the polymorphism had significantly higher platelet aggregation values than non-carriers of the rare allele after $2 \mu \mathrm{M}$ and $10 \mu \mathrm{M}$ ADP, and after arachidonic acid (AA) stimuli. In particular, homozygous subjects for the rare allele had significantly higher platelet aggregation after ADP stimuli than heterozygous carriers. The genotype distribution of CYP2C19 polymorphism significantly differed between patients with and without RPR evaluated by $10 \mu \mathrm{M}$ ADPinduced platelet aggregation. The prevalence of carriers of the rare allele was higher in patients with RPR by ADP than in patients without RPR by ADP. Similar results were also observed in patients with RPR by AA in contrast to patients without RPR by AA. Using a multivariate linear regression model (with ADP $2 \mu \mathrm{M}$ or ADP $10 \mu \mathrm{M}$ or $\log$ [AA] platelet aggregation as dependent variables and age, gender, hypertension, diabetes mellitus, dyslipidemia, and smoking habit

Table 2 Association of CYP2C19*2 loss-of-function polymorphism with response variability to clopidogrel treatment in high risk vascular patients

\begin{tabular}{|c|c|c|c|c|c|}
\hline Study & N subjects & Treatment & Functional evaluation & $\begin{array}{l}\text { CYP2C19*2 } \\
\text { carriers } \%\end{array}$ & Association \\
\hline Giusti et $\mathrm{al}^{37}$ & $1419 \mathrm{PCl}+$ stent & $\begin{array}{l}600 \mathrm{mg} \text { LD }+75 \mathrm{mg} / \text { day } \\
\text { maintaining }\end{array}$ & I0 $\mu \mathrm{M}$ ADP-induced PA & 31.4 & Yes \\
\hline Frere et $\mathrm{al}^{100}$ & 603 NSTE & $600 \mathrm{mg}$ LD & $\begin{array}{l}\text { I0 } \mu \text { M ADP-induced PAVASP ph } \\
\text { ADP-induced } \\
\text { P-selectin }\end{array}$ & 27.6 & Yes \\
\hline Trenk et $\mathrm{a}^{38}$ & $797 \mathrm{PCl}+$ stent & $\begin{array}{l}600 \mathrm{mg} \text { LD }+75 \mathrm{mg} / \text { day } \\
\text { maintaining }\end{array}$ & $\begin{array}{l}5 \mu \mathrm{M} \text { and } 20 \mu \mathrm{M} \text { ADP-induced PA } \\
\text { ADP-induced P-selectin, activated } \\
\text { GPIla/IIlb, CD63, CD40L, CD4I (GPIIb) }\end{array}$ & 30.7 & Yes \\
\hline Geisler et $\mathrm{al}^{101}$ & $237 \mathrm{PCl}$ & $\begin{array}{l}600 \mathrm{mg} \text { LD }+75 \mathrm{mg} / \text { day } \\
\text { maintaining }\end{array}$ & $20 \mu \mathrm{M}$ ADP-induced PA & 26.0 & Yes \\
\hline Gladding et al ${ }^{102}$ & $60 \mathrm{PCl}$ & $\begin{array}{l}600 / / 200 \mathrm{mg} \text { LD + } \\
75 / / 50 \mathrm{mg} / \text { day }\end{array}$ & VerifyNow ${ }^{\circledR}$ P2Y 12 & & Yes \\
\hline Jinnai et $\mathrm{al}^{103}$ & $30 \mathrm{PCl}$ Japanese & $\begin{array}{l}300 \mathrm{mg} \text { LD }+75 \mathrm{mg} / \text { day } \\
\text { maintaining }\end{array}$ & $5 \mu \mathrm{M}$ ADP-induced PA & 56.0 & Yes \\
\hline
\end{tabular}

Abbreviations: N, number; PCI, percutaneous coronary intervention; LD, loading dose; PA, platelet aggregation; NSTE, non-ST elevation; VASPph, vasodilator-stimulated phosphoprotein phosphorylation state of whole blood-we performed a dual color flow cytometric assay; GPlla/lllb, glycoprotein Ila/lllb (PAC-I); GPIlb, glycoprotein Ilb. 
as independent variables), age, diabetes and CYP2C19*2 polymorphisms remained significant and independent risk factors for antiplatelet treatment variability.

Several other groups have confirmed that the $* 2$ allele of the CYP2C19 gene is associated with higher platelet aggregability and RPR in similar and different clinical settings. In 603 patients with non-ST elevation ACS, Frere et al ${ }^{100}$ demonstrated that the CYP2C19*2 polymorphism influences post-treatment platelet reactivity and clopidogrel response assessed by ADP-induced platelet aggregation, VASP phosphorylation index, and ADP-induced P-selectin expression. Trenk et a ${ }^{138}$ studied and followed-up 797 patients undergoing elective coronary stent implantation and brought to light an association between CYP2C19*2 polymorphism and platelet function phenotype of high $(>14 \%)$ ADP residual platelet aggregation on clopidogrel.

Geisler et al ${ }^{101}$ observed that CYP2C $19 * 2$ carriers showed significantly increased residual platelet aggregation compared with noncarriers in 237 symptomatic CAD patients (both stable angina or ACS patients). In 60 patients undergoing elective PCI in the randomized Plavix Response in Coronary Intervention (PRINC) trial, Gladding et al ${ }^{102}$ measured platelet function using the VerifyNow ${ }^{\circledR}$ P2Y12 analyzer after a $600 \mathrm{mg}$ or split $1200 \mathrm{mg}$ loading dose and after a 75 or $150 \mathrm{mg}$ daily maintenance dosage. CYP2C19*1*1 carriers were shown to have greater platelet inhibition $2 \mathrm{~h}$ after a $600 \mathrm{mg}$ dose, compared with platelet inhibition in CYP2C19*2 or *4 carriers and CYP2C19*17 carriers. CYP2C19*2 or *4 carriers had greater platelet inhibition with the higher loading dose than with the lower dose at $4 \mathrm{~h}$ and responded better with the higher maintenance dose regimen. The association of the CYP2C19*2 polymorphism with a RPR was also observed in Japanese patients by Jinnai et $\mathrm{al}^{103}$ where a higher prevalence of carriers of the *2 allele was found $(56 \%)$ with respect to the Western countries' patients $(\sim 30 \%)$.

\section{Association of cytochrome P450 2CI 9 loss-of-function polymorphism with the occurrence of major adverse cardiovascular events}

Recently, different groups contemporarily demonstrated that CYP2C19*2 is a determinant of the occurrence of MACE and in particular of ST in different clinical settings and at different follow-up times (Table 3). ${ }^{39-43}$ Only one paper failed to demonstrate a role of the CYP2C19*2 loss-of-function polymorphism on the occurrence of MACE or ST. Indeed, Trenk et a ${ }^{38}$ do not demonstrate a relationship between $* 2$ polymorphism and increased occurrence of adverse 1-year clinical outcome (ie, death from any cause and myocardial infarction) of elective PCI with DES or BMS (Table 3).

Table 3 Association of CYP2C19*2 loss-of-function polymorphism with occurrence of major adverse cardiovascular events (MACE)

\begin{tabular}{|c|c|c|c|c|c|}
\hline Study & N subjects & Treatment & $\begin{array}{l}\text { Outcome } \\
\text { (follow-up) }\end{array}$ & CYP2CI 9 alleles & Association \\
\hline Trenk et a ${ }^{38}$ & $797 \mathrm{PCl}+$ stent & $\begin{array}{l}600 \mathrm{mg} \text { LD }+75 \mathrm{mg} / \text { day } \\
\text { maintaining }\end{array}$ & Death + MI (I year) & $* 2$ & No \\
\hline Simon et $\mathrm{a}^{39}$ & 2208 AMI (I 535 PCl) & $\begin{array}{l}300 \mathrm{mg} \text { mean } \mathrm{LD}+75 \mathrm{mg} / \text { day } \\
\text { maintaining }\end{array}$ & $\begin{array}{l}\text { Death + nonfatal stroke + } \\
\text { MI (I year) }\end{array}$ & $\begin{array}{l}\text { Any two of } \\
* 2, * 3, * 4, * 5\end{array}$ & $\begin{array}{l}\text { Yes }(H R=1.98) \\
\text { Yes }(H R=3.58)\end{array}$ \\
\hline \multirow[t]{2}{*}{ Mega et al ${ }^{40}$} & I 477 ACS & $\begin{array}{l}300 \mathrm{mg} \text { LD }+75 \mathrm{mg} / \text { day } \\
\text { maintaining }\end{array}$ & $\begin{array}{l}\text { Cardiovascular death }+ \text { MI } \\
+ \text { stroke ( } 15 \text { months })\end{array}$ & $* 2$ & Yes $(H R=1.53)$ \\
\hline & & & ST (I5 months) & & Yes $(H R=3.09)$ \\
\hline \multirow[t]{2}{*}{ Collet et $\mathrm{al}^{41}$} & $259 \mathrm{Ml}$ (<45 years) & $\begin{array}{l}600 \mathrm{mg} \text { LD }+75 \mathrm{mg} / \text { day } \\
\text { maintaining }\end{array}$ & $\begin{array}{l}\text { Death + MI + coro- } \\
\text { nary revascularization } \\
\text { ( } 6 \text { months) }\end{array}$ & $* 2$ & Yes $(H R=3.69)$ \\
\hline & & & ST (6 months) & & Yes $(H R=6.02)$ \\
\hline \multirow[t]{2}{*}{ Giusti et $\mathrm{a}^{42}$} & $772 \mathrm{PCl}+\mathrm{DES}$ & $\begin{array}{l}600 \mathrm{mg} \text { LD }+75 \mathrm{mg} / \text { day } \\
\text { maintaining }\end{array}$ & $\begin{array}{l}\text { Cardiovascular death }+ \text { ST } \\
\text { (6 months) }\end{array}$ & $* 2$ & Yes $(O R=2.70)$ \\
\hline & & & ST (6 months) & & Yes $(\mathrm{OR}=3.43)$ \\
\hline Sibbing et $\mathrm{al}^{43}$ & $2485 \mathrm{PCl}+$ stent & $\begin{array}{l}600 \mathrm{mg} \text { LD }+75 \mathrm{mg} / \mathrm{day} \\
\text { maintaining }\end{array}$ & ST (30 days) & $* 2$ & Yes $(H R=3.8 I)$ \\
\hline
\end{tabular}

Abbreviations: $\mathrm{N}$, number; LD, loading dose; $\mathrm{PCl}$, percutaneous coronary intervention; $\mathrm{Ml}$, myocardial infarction; $\mathrm{AMI}$, acute myocardial infarction; $\mathrm{ACS}$, acute coronary syndrome; ST, intra stent thrombosis; DES, drug-eluting stent; $H R$, hazard ratio; OR, odds ratio. 
They showed an association between CYP2C19*2 polymorphism and platelet function phenotype, as well as an association of high on-clopidogrel platelet reactivity with poor clinical outcome. On the other hand, in their patient population they had only 280 patients out of 797 with at least 1 DES. In the group of patients with at least 1 DES, the percentage of patients with an event was 3.3\% (3 of 90) among the carriers of the $* 2$ allele versus $2.1 \%$ (4 of 190 ) of the wild-type homozygotes $(P=0.684)$.

In 2208 patients with an AMI and on-clopidogrel therapy, Simon et al ${ }^{39}$ assessed the relation of allelic variants of genes modulating clopidogrel absorption (ATP-binding cassette, sub-family B [MDR/TAP], member 1 [ABCB1]), metabolic activation (CYP3A5 and CYP2C19), and biologic activity (P2Y12 and integrin, beta 3 [ITGB3]) to the risk of death from any cause, nonfatal stroke, or myocardial infarction during 1 year of follow-up. Patients with two variant alleles of ABCB1 (TT genotype) had a higher rate of cardiovascular events at 1 year than those with the ABCB1 wild-type genotype (CC) $(15.5 \%$ vs $10.7 \%$; adjusted hazard ratio $[\mathrm{HR}]=1.72,95 \% \mathrm{CI}$ : 1.20-2.47). Moreover, they demonstrated that patients carrying CYP2C19 loss-of-function alleles $(* 2, * 3, * 4$ or $* 5)$ had a higher rate of subsequent cardiovascular events during 1year of follow-up (HR $=1.98,95 \%$ CI: $1.10-3.58$ ) than those who were not. The presence of two variant alleles of CYP2C19, but not $\mathrm{ABCB} 1$, was found to be associated with an increase by a factor of 3.58 (95\% CI: 1.71-7.51) in the rate of cardiovascular events among the 1535 patients who underwent PCI during hospitalization as compared with those who did not.

Mega et $\mathrm{al}^{40}$ tested the association between functional genetic variants in CYP genes (CYP2C19, CYP2C9, CYP2B6, CYP3A5, CYP3A4, CYP1A2) and cardiovascular outcomes in 1477 subjects with ACS who were treated with clopidogrel in the TRITON-TIMI 38 trial. They demonstrated that carriers of the reduced-function CYP2C19*2 allele had significantly lower levels of the active metabolite of clopidogrel, diminished platelet inhibition, and a higher rate of MACE at 15 months (death from cardiovascular causes, myocardial infarction or stroke; HR $=1.53,95 \%$ CI: 1.07-2.19), as well as an increase by a factor of 3 in the risk of ST (HR $=3.09,95 \%$ CI: 1.19-8.00).

In 259 young patients ( $<45$ years) who survived a first myocardial infarction and were exposed to clopidogrel treatment for at least one month, Collet et $\mathrm{a}^{41}$ assessed whether the CYP2C19*2 polymorphism affected long-term prognosis of patients who were chronically treated with clopidogrel. They chose, as their primary end-point, a composite of cardiovascular death, nonfatal myocardial infarction, and urgent revascularization occurring during exposure to clopidogrel and as a secondary end-point, ST. In this cohort of premature myocardial infarction patients, the primary end-point occurred more frequently in carriers than in noncarriers (15 vs 11 events; $\mathrm{HR}=3.69,95 \%$ CI: $1.69-8.05, P=0.0005$ ). Similar results were obtained in relation to the secondary end-point for which they observed an increase by a factor of 6 in the risk of ST ( 8 vs 4 events; HR $=6.02,95 \% \mathrm{CI}$ : 1.81-20.04, $P=0.0009$ ). After multivariable stepwise Cox regression analysis considering in the model baseline characteristics, especially those known to be associated with recurrent acute coronary thrombosis and poor response to clopidogrel (ie, body mass index, smoking status, diabetes status, stent implantation, initial ST-segment elevation myocardial infarction, and use of proton pump inhibitors), the CYP2C19*2 genetic variant was the only independent predictor of cardiovascular events $(\mathrm{HR}=4.04,95 \% \mathrm{CI}$ : $1.81-9.02, P=0.0006)$.

In the framework of the RECLOSE trial, Giusti et al ${ }^{42}$ evaluated the role of the CYP2C19*2 polymorphism on the occurrence of drug-eluting ST (primary end-point) and the composite feature of cardiac mortality and drugeluting ST (secondary end-point) in a 6-month follow-up of 772 patients undergoing PCI on dual antiplatelet treatment. Patients with ST or the composite of cardiac mortality and ST showed a higher prevalence of carriers of the rare allele (54.1\% vs $31.3 \% ; P=0.025$ and $51.7 \%$ vs $31.2 \% ; P=0.020$, respectively). In this clinical setting of high risk vascular patients, the authors demonstrated that the CYP2C19*2 polymorphism was an independent risk factor for ST when the effect of the polymorphism was evaluated in a model adjusted for high on-clopidogrel platelet reactivity evaluated by ADP-induced platelet aggregation (ADP-RPR), traditional cardiovascular risk factors, and clinical and procedural risk factors for ST (eg, total chronic occlusion, multivessel disease, bifurcation lesion, AMI, previous myocardial infarction, total stent length, and left ventricular ejection fraction) (OR $=3.43,95 \%$ CI: 1.01-12.78). Moreover, subjects with the contemporary presence of the CYP2C19*2 allele and ADP-RPR exhibited a strong risk of ST or ST and cardiac mortality (OR $=5.79,95 \%$ CI: $1.04-39.01$ and $11.45,95 \%$ CI: 1.84-71.27, respectively).

Finally, Sibbing et $a 1^{43}$ assessed the impact of the CYP2C19 loss-of-function polymorphism on ST following PCI performed after pre-treatment with clopidogrel on 2485 patients with CAD undergoing PCI. The primary endpoint of the study was the incidence of definite ST within 30 days following PCI. The cumulative 30-day incidence of 
ST was significantly higher in CYP2C19*2 allele carriers $(* 1 / * 2$ heterozygotes or $* 2 / * 2$ homozygotes) vs CYP2C19 wild-type homozygotes $(* 1 / * 1)(1.5 \%$ in CYP2C19*2 allele carriers vs $0.4 \%$ in CYP2C19 wild-type homozygotes, $\mathrm{HR}=3.81,95 \% \mathrm{CI}: 1.45-10.02, P=0.006$ after adjustment for confounding variables). The risk of ST was highest (2.1\%) in patients with the CYP $2 \mathrm{C} 19 * 2 / * 2$ genotype $(P=0.002)$.

Recently, Sofi et $\mathrm{al}^{104}$ performed a meta-analysis on data available for a total of 7950 patients from 6 cohort prospective studies who were followed for a time ranging from 6 months to 8.4 years. ${ }^{38-43}$ Their findings reinforced the observation that the CYP2C19*2 polymorphism is associated with the increased risk of MACE, particularly ST. The summary risk ratios for included cohort prospective studies showed a significant association between the CYP2C19*2 polymorphism and an increased risk of MACE in the followup (relative risk $[\mathrm{RR}]=1.80,95 \% \mathrm{CI}: 1.02-3.19, P=0.04$ ). When studies evaluating ST $(\mathrm{N}=4)$ for a total of 4975 patients were considered, the presence of the variant allele was associated with an increased risk of ST $(\mathrm{RR}=2.82$, 95\% CI: $1.43-5.56, P=0.0001)$.

\section{Towards a tailored antiplatelet therapy by optimizing response to clopidogrel in ACS}

Due to the large body of evidence accumulated, the issue could be raised whether the identification of CYPC19*2 carriers is appropriate to improve the risk stratification and therapeutic management of patients, and consequently a reduction of the occurrence of MACE, particularly ST, in patients with ACS. Several strategies could be considered to solve the problem of the high on-treatment platelet reactivity despite the dual antiplatelet treatment in high risk vascular patients including administering a higher dosage of clopidogrel or a different antiplatelet drug from those presently available (prasugrel, ticagrelor), and/or the addition of a third antiplatelet drug such as cilostazol.

Bonello et al $^{105}$ determined that a tailored loading dose of clopidogrel to obtain a VASP index $<50 \%$ after a first $600 \mathrm{mg}$ loading dose in patients with high on-treatment platelet reactivity translated in an improved outcome. ${ }^{105,106}$ Patients with a VASP $<50 \%$ after the first clopidogrel loading dose were considered good responders. Patients with a VASP $\geq 50 \%$, despite the $600 \mathrm{mg}$ loading dose, were considered to have high on-treatment platelet reactivity. For these patients, clopidogrel was adjusted individually, before PCI, to obtain a VASP index $<50 \%$ using up to 3 additional loading doses of $600 \mathrm{mg}$ each, prescribed at 24 hour intervals. Recently, the same investigators observed that high on-treatment platelet reactivity in homozygotes for CYP 2C19*2 loss-of-function polymorphism could be overcome using dose adjustment according to platelet reactivity monitoring. ${ }^{107}$

Regarding new antiplatelets, the TRITON-TIMI 38 trial demonstrated that, compared with clopidogrel, treatment with prasugrel resulted in a significantly lower rate of ischemic events and more bleeding among patients presenting with ACS with planned PCI. ${ }^{45}$ Both clopidogrel and prasugrel are pro-drugs that require biotransformation to active metabolites by CYP450 enzymes. Although the active metabolites of both drugs have similar affinity for the P2Y12 receptor in vitro, the in vivo differences in response appear to be mediated predominantly by differences in the metabolic pathways leading to the formation of the active metabolites. ${ }^{108}$ Esterases shunt the majority of clopidogrel to a dead-end inactive pathway, with the remaining pro-drug requiring two separate CYPdependent oxidative steps. ${ }^{52}$ In contrast, esterases are part of the activation pathway with prasugrel, which is oxidized to its active metabolite in a single CYP-dependent step, without an apparent dead-end inactive pathway. ${ }^{109}$ Among 238 healthy subjects, Mega et al ${ }^{110}$ did not observe significant attenuation of the pharmacokinetic or the pharmacodynamic response to prasugrel in carriers versus noncarriers of at least 1 reducedfunction allele for any of the CYP genes tested (CYP2C19, CYP2C9, CYP2B6, CYP3A5, CYP1A2). Consistent with these findings, in 1466 patients with ACS treated with prasugrel, no significant associations were found between any of the tested CYP genotypes and risk of cardiovascular death, myocardial infarction, or stroke. ${ }^{110}$

Several important issues should be considered in evaluating the possibility of a tailored therapy that takes in account the knowledge of CYP2C19*2 genotype. For instance, the result of the genotyping test should be available at the time of starting clopidogrel and during the early high risk phase of the ACS, together with the evaluation of the phenotype, such as ADP-induced platelet aggregation, ${ }^{14,15,53,111}$ Use of the VerifyNow ${ }^{\circledR}$ System, ${ }^{16,17}$ the more specific flow cytometric assay of P2Y12-mediated effect on phosphorilation of VASP in PGE1-treated platelet, ${ }^{53,106}$ or a more global approach, such as Multiplate whole blood aggregometry should be considered. ${ }^{112}$ The functional evaluation of the high on-clopidogrel platelet reactivity has the potential benefit of identifying those patients who are homozygous for the wild-type CYP2C19*1 allele, but they may still have a poor pharmacodynamic response to clopidogrel. In fact, the data 
by Giusti et $\mathrm{al}^{42}$ indicated that the contemporary presence of ADP-RPR and the CYP2C19*2 polymorphism was the strongest predictor of ST complication or the composite endpoint of ST and cardiac mortality with respect to the CYP2C19*2 polymorphism and ADP-RPR per se. These findings provide two insights: 1) mining of the CYP2C19*2 polymorphism as a risk factor for ST is only partially linked to its role in determining the ADP-RPR phenotype observed in the acute periprocedural phase, and 2) other genetic and acquired determinants of RPR in addition to the CYP2C19*2 polymorphism might have a role in determining the clinical outcome in these high risk vascular patients.

Several new drugs that target P2Y12 are now available (eg, prasugrel, ticagrelor, cangrelor). These drugs achieve consistently high levels of receptor inhibition, and may potentially provide solutions to the problem of variability in response to clopidogrel. Nevertheless, the possibility of a higher incidence of bleeding, other drug-drug interaction, and possible nonresponsiveness due to other genetic or acquired factors needs to be further explored for these new drugs.

\section{Conclusion}

In conclusion, a large body of evidence demonstrates that the CYP2C19*2 genetic variant is a major determinant of prognosis in high risk vascular patients who have undergone PCI and received clopidogrel treatment. Available data underscore the urgent need for prospective studies aimed at clarifying whether a more intense clopidogrel therapy or the use of a different drug (eg, prasugrel) designed for correction of inadequate suppression of platelet reactivity could improve the outcome, and incidence of MACE, in particular of ST, in high risk vascular patients without increasing the major bleeding complications. Aside from the traditional cardiovascular risk factors, and the clinical and procedural risk factors for MACE and ST, these studies should take into account the patient's genetic profile, platelet

\section{Required patient information}

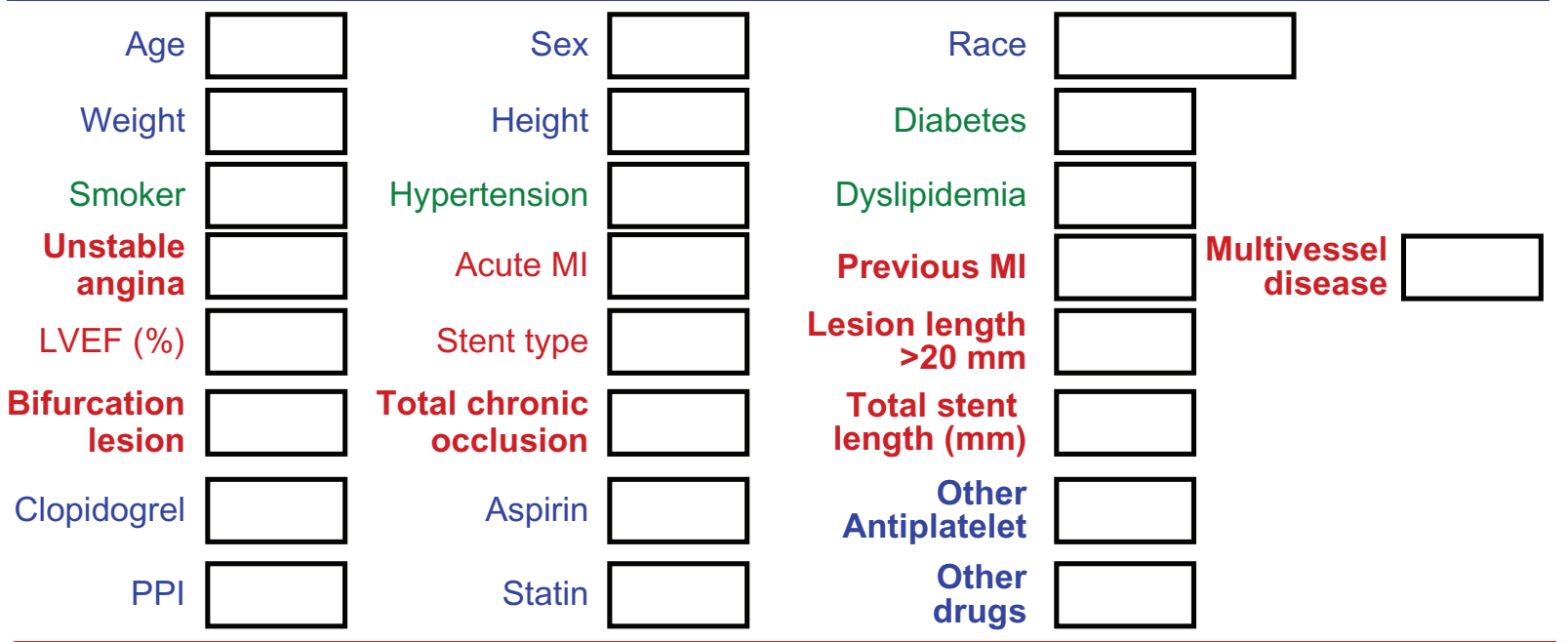

Platelet functional tests

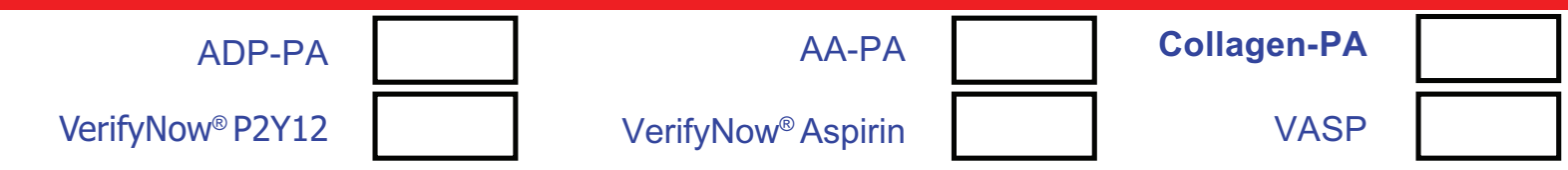

Genetic information

$\begin{array}{clll}\text { CYP2C19 } & \text { ABCB1 } \square & \text { CYP2C9 } \\ \text { Other genetic variants } & & \\ & \text { ESTIMATE }\end{array}$

Figure 3 Proposed form to collect patient information for the algorithm estimating individual risk and best personalized therapeutic strategy.

Abbreviations: MI, myocardial infarction; LVEF, left ventricular ejection fraction; PPI, proton pump inhibitor; ADP-PA, platelet aggregation induced by ADP; AA-PA, platelet aggregation induced by arachidonic acid; collagen-PA, platelet aggregation induced by collagen. 
phenotype, and possible drug-drug interactions (especially with drugs metabolized by the same CYP450 isoforms) to identify the best pharmacological strategy for the efficacious management and safety of these high risk vascular patients. In the near future, we can imagine an algorithm (Figure. 3) that takes these factors into account and scores the weight of each genetic or acquired determinant of the aggressive phenotype of the platelets, along with other clinical and procedural risk factors for cardiovascular complications, including drug-drug interactions. Such an algorithm could help clinicians to better predict overall risk and to apply the best therapeutic strategy for each patient.

\section{Disclosures}

The authors report no conflicts of interest in this work.

\section{References}

1. Mehta SR, Yusuf S, Peters RJ, et al. Effects of pretreatment with clopidogrel and aspirin followed by long-term therapy in patients undergoing percutaneous coronary intervention: the PCI-CURE study. Lancet. 2001;358(9281):527-533.

2. Steinhubl SR, Berger PB, Mann JT III, et al. Early and sustained dual oral antiplatelet therapy following percutaneous coronary intervention: a randomized controlled trial. JAMA. 2002;288:2411-2420.

3. Bhatt DL, Bertrand ME, Berger PB, et al. Meta-analysis of randomized and registry comparison of ticlopidine with clopidogrel after stenting. $J$ Am Coll Cardiol. 2002;39(1):9-14.

4. McFadden EP, Stabile E, Regar E, et al. Late thrombosis in drug-eluting coronary stents after discontinuation of antiplatelet therapy. Lancet. 2004;364:1519-1521.

5. Kaiser C, Brunner-La Rocca HP, Buser PT, et al. Incremental costeffectiveness of drug-eluting stents compared with a third generation bare-metal stents in a real-world setting: Randomised Basel Stent Kosten Effektivitats Trial (BASKET). Lancet. 2005;366:921-929.

6. Iakovou I, Schmidt T, Bonizzoni E, et al. Incidence, predictors, and outcome of thrombosis after successful implantation of drug-eluting stents. JAMA. 2005;293:2126-2130.

7. Park DW, Park SW, Park KH, et al. Frequency and risk factors for stent thrombosis after drug-eluting stent omplantation during longterm follow-up. Am J Cardiol. 2006;98:352-356.

8. Matetzky S, Shenkman B, Guetta V, et al. Clopidogrel resistance is associated with increased risk of recurrent atherothrombotic events in patients with acute myocardial infarction. Circulation. 2004;109: 3171-3175.

9. Gurbel PA, Bliden KP, Samara W, et al. Clopidogrel effect on platelet reactivity in patients with stent thrombosis. J Am Coll Cardiol. 2005; 46:1827-1832.

10. Gurbel PA, Bliden KP, Guyer K, et al. Platelet reactivity in patients and recurrent events post-stenting. $J$ Am Coll Cardiol. 2005;46: $1820-1826$.

11. Ajzenberg N, Aubry P, Huisse MG, et al. Enhanced shear-induced platelet aggregation in patients who experienced stent thrombosis. $J A m$ Coll Cardiol. 2005;45:1753-1756.

12. Cuisset T, Frere C, Quilici J, et al. High post-treatment platelet reactivity identified low-responders to dual antiplatelet therapy at increased risk of recurrent cardiovascular events after stenting for acute coronary syndrome. J Thromb Haemost. 2006;4:542-549.

13. Hochholzer W, Trenk D, Bestehorn HP, et al. Impact of the degree of peri-interventional platelet inhibition after loading with clopidogrel on early clinical outcome of elective coronary stent placement. $J$ Am Coll Cardiol. 2006;48:1742-1750.
14. Buonamici P, Marcucci R, Migliorini A, et al. Impact of platelet reactivity following clopidogrel administration on drug-eluting stent thrombosis. J Am Coll Cardiol. 2007;49:2312-2317.

15. Gori AM, Marcucci R, Migliorini A, et al. Incidence and clinical impact of dual nonresponsiveness to aspirin and clopidogrel in patients with drug-eluting stents. J Am Coll Cardiol. 2008;52:734-739.

16. Price MJ, Endemann S, Gollapudi RR, et al. Prognostic significance of post-clopidogrel platelet reactivity assessed by a point-of-care assay on thrombotic events after drug-eluting stent implantation. Eur Heart $J$. 2008;29:992-1000.

17. Marcucci R, Gori AM, Paniccia R, et al. Cardiovascular death and nonfatal myocardial infarction in acute coronary syndrome patients receiving coronary stenting are predicted by residual platelet reactivity to ADP detected by a point-of-care assay: a 12-month follow-up. Circulation. 2009;119:237-242.

18. Sibbing D, Braun S, Morath T, et al. Platelet reactivity after clopidogrel treatment assessed with point-of-care analysis and early drug-eluting stent thrombosis. J Am Coll Cardiol. 2009;53:849-856.

19. Sofi F, Marcucci R, Gori AM, Giusti B, Abbate R, Gensini GF. Clopidogrel nonresponsiveness and risk of cardiovascular morbidity: an updated meta-analysis. Thromb Haemost. In press 2009.

20. Gurbel PA, Antonino MJ, Tantry US. Recent developments in clopidogrel pharmacology and their relation to clinical outcomes. Expert Opin Drug Metab Toxicol. 2009;5:989-1004.

21. Juurlink DN, Gomes T, Ko DT, et al. A population-based study of the drug interaction between proton pump inhibitors and clopidogrel. CMAJ. 2009;180:713-718.

22. O'Donoghue ML, Braunwald E, Antman EM, et al. Pharmacodynamic effect and clinical efficacy of clopidogrel and prasugrel with or without a proton-pump inhibitor: an analysis of two randomised trials. Lancet. 2009;374:989-997.

23. Sibbing D, Morath T, Stegherr J, et al. Impact of proton pump inhibitors on the antiplatelet effects of clopidogrel. Thromb Haemost. 2009;101:714-719.

24. Ho PM, Maddox TM, Wang L, et al. Risk of adverse outcomes associated with concomitant use of clopidogrel and proton pump inhibitors following acute coronary syndrome. JAMA. 2009;301:937-944.

25. Gori AM, Cesari F, Marcucci R, et al. The balance between pro- and antiinflammatory cytokines is associated with platelet aggregability in acute coronary syndrome patients. Atherosclerosis. 2009;202:255-262.

26. Cesari F, Marcucci R, Caporale R, et al. Relationship between high platelet turnover and platelet function in high risk patients with coronary artery disease on dual antiplatelet therapy. Thromb Haemost. 2008;99: 930-935.

27. Guthikonda S, Alviar CL, Vaduganathan M, et al. Role of reticulated platelets and platelet size heterogeneity on platelet activity after dual antiplatelet therapy with aspirin and clopidogrel in patients with stable coronary artery disease. J Am Coll Cardiol. 2008;52:743-749.

28. Mannini L, Marcucci R, Paniccia R, et al. Erythrocyte deformability and white blood cell count are associated with aspirin resistance in high risk vascular patients. Clin Hemorheol Microcirc. 2006;35:175-181.

29. Cecchi E, Marcucci R, Paniccia R, et al. Effect of blood hematocrit and erythrocyte deformability on adenosine 5'-diphosphate platelet reactivity in patients with acute coronary syndromes on dual antiplatelet therapy. Am J Cardiol. 2009;104:764-768.

30. Marcucci R, Cesari F, Cinotti S, et al. ADAMTS-13 activity in the presence of elevated von Willebrand factor levels as a novel mechanism of residual platelet reactivity in high risk coronary patients on antiplatelet treatment. Thromb Res. 2008;123:130-136.

31. Nguyen TA, Diodati JG, Pharand C. Resistance to clopidogrel: a review of the evidence. J Am Coll Cardiol. 2005;45:1157-1164.

32. Szczeklik A, Musial J, Undas A, Sanak M. Aspirin resistance. JThromb Haemost. 2005;3:1655-1662.

33. Giusti B, Gori AM, Marcucci R, et al. Role of glycoprotein Ia gene polymorphisms in determining platelet function in myocardial infarction patients undergoing percutaneous coronary intervention on dual antiplatelet treatment. Atherosclerosis. 2008;196:341-348. 
34. Fatini C, Sticchi E, Bolli P, et al. Platelet aggregability is modulated by eNOS locus in non-type 2 diabetic patients with acute coronary syndrome. Nutr Metab Cardiovasc Dis. 2009 Oct 8; doi:10.1016/ j.numecd.2009.07.001.

35. Hulot JS, Bura A, Villard E, et al. Cytochrome P450 2C19 loss-offunction polymorphism is a major determinant of clopidogrel responsiveness in healthy subjects. Blood. 2006;108:2244-2247.

36. Brandt JT, Close SL, Iturria SJ, et al. Common polymorphisms of CYP2C19 and CYP2C9 affect the pharmacokinetic and pharmacodynamic response to clopidogrel but not prasugrel. J Thromb Haemost. 2007;5:2429-2436.

37. Giusti B, Gori AM, Marcucci R, et al. Cytochrome P450 2C19 loss-offunction polymorphism, but not CYP3A4 IVS10 + 12G/A and P2Y12 T744C polymorphisms, is associated with response variability to dual antiplatelet treatment in high risk vascular patients. Pharmacogenet Genomics. 2007;17:1057-1064.

38. Trenk D, Hochholzer W, Fromm MF, et al. Cytochrome P450 2C19 $681 \mathrm{G}>$ A polymorphism and high on-clopidogrel platelet reactivity associated with adverse 1-year clinical outcome of elective percutaneous coronary intervention with drug-eluting or bare-metal stents. $J \mathrm{Am}$ Coll Cardiol. 2008;51:1925-1934.

39. Simon T, Verstuyft C, Mary-Krause M, et al. Genetic determinants of response to clopidogrel and cardiovascular events. $N$ Engl J Med. 2009;360:363-375.

40. Mega JL, Close SL, Wiviott SD, et al. Cytochrome p-450 polymorphisms and response to clopidogrel. $N$ Engl J Med. 2009;360: 354-362.

41. Collet JP, Hulot JS, Pena A, et al. Cytochrome P450 2C19 polymorphism in young patients treated with clopidogrel after myocardial infarction: a cohort study. Lancet. 2009;373:309-317.

42. Giusti B, Gori AM, Marcucci R, et al. Relation of cytochrome P450 2C19 loss-of-function polymorphism to occurrence of drug-eluting coronary stent thrombosis. Am J Cardiol. 2009;103:806-811.

43. Sibbing D, Stegherr J, Latz W, et al. Cytochrome P450 2C19 loss-offunction polymorphism and stent thrombosis following percutaneous coronary intervention. Eur Heart J. 2009;30:916-922.

44. Gurbel PA, Tantry US. Prasugrel, a third generation thienopyridine and potent platelet inhibitor. Curr Opin Investig Drugs. 2008;9:324-336.

45. Wiviott SD, Braunwald E, McCabe $\mathrm{CH}$, et al. Prasugrel versus clopidogrel in patients with acute coronary syndromes. $N$ Engl $\mathrm{J} \mathrm{Med}$. 2007:357:2001-2015.

46. Wallentin L, Becker RC, Budaj A, et al. Ticagrelor versus clopidogrel in patients with acute coronary syndromes. $N$ Engl J Med. 2009;361: 1045-1057.

47. Gachet C. P2 receptors, platelet function and pharmacological implications. Thromb Haemost. 2008;99:466-472.

48. Jin J, Kunapuli SP. Coactivation of two different G protein-coupled receptors is essential for ADP-induced platelet aggregation. Proc Natl Acad Sci U S A. 1998;95:8070-8074.

49. Pereillo JM, Maftouh M, Andrieu A, et al. Structure and stereochemistry of the active metabolite of clopidogrel. Drug Metab Dispos. 2002;30:1288-1295.

50. Savi P, Zachayus JL, Delesque-Touchard N, et al. The active metabolite of Clopidogrel disrupts P2Y12 receptor oligomers and partitions them out of lipid rafts. Proc Natl Acad Sci U SA. 2006;103:11069-11074.

51. Ding Z, Kim S, Dorsam RT, Jin J, Kunapuli SP. Inactivation of the human P2Y12 receptor by thiol reagents requires interaction with both extracellular cysteine residues, Cys17 and Cys270. Blood. 2003;101:3908-3914.

52. Kazui M, Nishiya Y, Ishizuka T, et al. Identification of the human cytochrome P450 enzymes involved in the two oxidative steps in the bioactivation of clopidogrel to its pharmacologically active metabolite. Drug Metab Dispos. 2009 Oct 7; doi:10.1124/dmd.109.029132.

53. Paniccia R, Antonucci E, Gori AM, et al. Different methodologies for evaluating the effect of clopidogrel on platelet function in high risk coronary artery disease patients. J Thromb Haemost. 2007;5:1839-1847.
54. Paniccia R, Antonucci E, Gori AM, et al. Comparison of different methods to evaluate the effect of aspirin on platelet function in high risk patients with ischemic heart disease receiving dual antiplatelet treatment. Am J Clin Pathol. 2007;128:143-149.

55. Snoep JD, Hovens MM, Eikenboom JC, van der Bom JG, Jukema JW, Huisman MV. Clopidogrel nonresponsiveness in patients undergoing percutaneous coronary intervention with stenting: a systematic review and meta-analysis. Am Heart J. 2007;154:221-231.

56. Patti G, Nusca A, Mangiacapra F, Gatto L, D’Ambrosio A, Di Sciascio G. Point-of-care measurement of clopidogrel responsiveness predicts clinical outcome in patients undergoing percutaneous coronary intervention: results of the ARMYDA-PRO (Antiplatelet therapy for reduction of Myocardial Damage during Angioplasty-Platelet Ractivity Predicts Outcome) study. J Am Coll Cardiol. 2008;52:1128-1133.

57. Gurbel PA, Bliden KP, Hayes KM, Yoho JA, Herzog WR, Tantry US. The relation of dosing to clopidogrel responsiveness and the incidence of high post-treatment platelet aggregation in patients undergoing coronary stenting. J Am Coll Cardiol. 2005;45:1392-1396.

58. von Beckerath N, Taubert D, Pogatsa-Murray G, Schömig E, Kastrati A, Schömig A. Absorption, metabolization, and antiplatelet effects of 300-, 600-, and 900-mg loading doses of clopidogrel: results of the ISARCHOICE (Intracoronary Stenting and Antithrombotic Regimen: Choose Between 3 High Oral Doses for Immediate Clopidogrel Effect) Trial. Circulation. 2005;112:2946-2950.

59. Angiolillo DJ, Shoemaker SB, Desai B, et al. Randomized comparison of a high clopidogrel maintenance dose in patients with diabetes mellitus and coronary artery disease: results of the Optimizing Antiplatelet Therapy in Diabetes Mellitus (OPTIMUS) study. Circulation. 2007; 13(115):708-716.

60. Lau WC, Gurbel PA, Watkins PB, Neer CJ, Hopp AS, Carville DG. Contribution of hepatic cytochrome P450 3A4 metabolic activity to the phenomenon of clopidogrel resistance. Circulation. 2004;109: 166-171.

61. Kuchulakanti PK, Chu WW, Torguson R, et al. Correlates and longterm outcomes of angiographically proven stent thrombosis with sirolimus- and paclitaxel-eluting stents. Circulation. 2006;113: 1108-1113.

62. Hamann GF, Weimar C, Glahn J, Busse O, Diener HC; German Stroke Data Bank. Adherence to secondary stroke prevention strategiesresults from the German Stroke Data Bank. Cerebrovasc Dis. 2003;15: 282-288.

63. Serebruany VL. The "clopidogrel resistance" trap. Am J Cardiol. 2007:100:1044-1046.

64. Serebruany V, Cherala G, Williams C, et al. Association of platelet responsiveness with clopidogrel metabolism: role of compliance in the assessment of "resistance". Am Heart J. 2009 Dec;158(6):925-932.

65. Lau WC, Waskell LA, Watkins PB, Neer CJ, Horowitz K, Hopp AS. Atorvastatin reduces the ability of clopidogrel to inhibit platelet aggregation: a new drug-drug interaction. Circulation. 2003;107:32-37.

66. Saw J, Steinhubl SR, Berger PB, et al. Lack of adverse clopidogrelatorvastatin clinical interaction from secondary analysis of a randomized placebo-controlled clopidogrel trial. Circulation. 2003;108:921-924.

67. Serebruany VL, Midei MG, Malinin AI, et al. Absence of interaction between atorvastatin or other statin and clopidogrel: results from the interaction study. Arch Intern Med. 2004;164:2051-2057.

68. Gilard M, Arnaud B, Cornily JC, et al. Influence of omeprazole on the antiplatelet action of clopidogrel associated with aspirin: the randomized, double-blind OCLA (Omeprazole CLopidogrel Aspirin) study. J Am Coll Cardiol. 2008;51:256-260.

69. Siller-Matula JM, Spiel AO, Lang IM, Kreiner G, Christ G, Jilma B. Effects of pantoprazole and esomeprazole on platelet inhibition by clopidogrel. Am Heart J. 2009;157:148.e1-e5.

70. Norgard NB, Mathews KD, Wall GC. Drug-drug interaction between clopidogrel and the proton pump inhibitors. Ann Pharmacother. 2009;43:1266-1274. 
71. Pauli-Magnus C, Rekersbrink S, Klotz U, Fromm MF. Interaction of omeprazole, lansoprazole and pantoprazole with P-glycoprotein. Naunyn Schmiedebergs Arch Pharmacol. 2001;364:551-557.

72. Taubert D, von Beckerath N, Grimberg G, et al. Impact of P-glycoprotein on clopidogrel absorption. Clin Pharmacol Ther. 2006;80: 486-501.

73. Gilard M, Arnaud B, Le Gal G, Abgrall JF, Boschat J. Influence of omeprazol on the antiplatelet action of clopidogrel associated to aspirin. J Thromb Haemost. 2006;4:2508-2509.

74. Cuisset T, Frere C, Quilici J, et al. Comparison of omeprazole and pantoprazole influence on a high 150-mg clopidogrel maintenance dose the PACA (Proton Pump Inhibitors And Clopidogrel Association) prospective randomized study. J Am Coll Cardiol. 2009;54: 1149-1153.

75. Taubert D, Kastrati A, Harlfinger S, et al. Pharmacokinetics of clopidogrel after administration of a high loading dose. Thromb Haemost. 2004;92:311-316.

76. Geisler T, Grass D, Bigalke B, et al. The Residual Platelet Aggregation after Deployment of Intracoronary Stent (PREDICT) score. J Thromb Haemost. 2008;6:54-61.

77. Li YG, Ni L, Brandt JT, et al. Inhibition of platelet aggregation with prasugrel and clopidogrel: an integrated analysis in 846 subjects. Platelets. 2009;20:316-327.

78. Gremmel T, Steiner S, Seidinger D, Koppensteiner R, Panzer S, Kopp CW. Adenosine diphosphate-inducible platelet reactivity shows a pronounced age dependency in the initial phase of antiplatelet therapy with clopidogrel. J Thromb Haemost. 2009 Oct 10; doi:10.1111/j.15387836.2009.03644.

79. Price MJ, Nayak KR, Barker CM, Kandzari DE, Teirstein PS. Predictors of heightened platelet reactivity despite dual-antiplatelet therapy in patients undergoing percutaneous coronary intervention. Am J Cardiol. 2009;103:1339-1343.

80. Angiolillo DJ, Suryadevara S. Aspirin and clopidogrel: efficacy and resistance in diabetes mellitus. Best Pract Res Clin Endocrinol Metab. 2009;23:375-388.

81. Angiolillo DJ, Bernardo E, Ramírez C, et al. Insulin therapy is associated with platelet dysfunction in patients with type 2 diabetes mellitus on dual oral antiplatelet treatment. J Am Coll Cardiol. 2006;48:298-304.

82. Geisler T, Anders N, Paterok M, et al. Platelet response to clopidogrel is attenuated in diabetic patients undergoing coronary stent implantation. Diabetes Care. 2007;30:372-374.

83. Serebruany V, Pokov I, Kuliczkowski W, Chesebro J, Badimon J. Baseline platelet activity and response after clopidogrel in 257 diabetics among 822 patients with coronary artery disease. Thromb Haemost 2008;100:76-82.

84. Marcucci R, Gori AM, Paniccia R, et al. Residual platelet reactivity is associated with clinical and laboratory characteristics in patients with ischemic heart disease undergoing PCI on dual antiplatelet therapy. Atherosclerosis. 2007;195:e217-23.

85. Antonino MJ, Mahla E, Bliden KP, Tantry US, Gurbel PA. Effect of long-term clopidogrel treatment on platelet function and inflammation in patients undergoing coronary arterial stenting. Am J Cardiol. 2009;103:1546-1550.

86. Guthikonda S, Lev EI, Patel R, et al. Reticulated platelets and uninhibited COX-1 and COX-2 decrease the antiplatelet effects of aspirin. J Thromb Haemost. 2007;5:490-496.

87. Lakkis N, Dokainish H, Abuzahra M, et al. Reticulated platelets in acute coronary syndrome: a marker of platelet activity. J Am Coll Cardiol. 2004;44:2091-2093.

88. McCabe DJ, Harrison P, Sidhu PS, Brown MM, Machin SJ. Circulating reticulated platelets in the early and late phases after ischaemic stroke and transient ischaemic attack. Br J Haematol. 2004;126:861-869.

89. Dong JF. Cleavage of ultralarge von Willebrand factor by ADAMTS-13 under flow conditions. J Thromb Haemost. 2005;3:2536-2544.

90. Vischer UM. Von Willebrand factor, endothelial dysfunction and cardiovascular disease. J Thromb Haemost. 2006;4:1186-1193.
91. Arya M, Anvari B, Romo GM, et al. Ultralarge multimers of von Willebrand factor form spontaneous high-strenght bonds with the platelet glycoprotein Ib-IX complex: studies using optical tweezers. Blood. 2002;99:3971-3977.

92. Furlan M. Von Willebrand factor: molecular size and functional activity. Ann Hematol. 1996;76:341-348.

93. Homoncik M, Jilma B, Eichelberger B, Panzer S. Inhibitory activity of aspirin on von Willebrand factor-induced platelet aggregation. Thromb Res. 2000;99:461-466

94. de Morais SM, Wilkinson GR, Blaisdell J, Nakamura K, Meyer UA, Goldstein JA. The major genetic defect responsible for the polymorphism of S-mephenytoin metabolism in humans. J Biol Chem. 1994;269:15419-15422.

95. Xie HG, Kim RB, Wood AJ, Stein CM. Molecular basis of ethnic differences in drug disposition and response. Ann Rev Pharmacol Toxicol. 2001;41:815-850.

96. Fontana P, Hulot JS, De Moerloose P, Gaussem P. Influence of CYP2C19 and CYP3A4 gene polymorphisms on clopidogrel responsiveness in healthy subjects. J Thromb Haemost. 2007;5:2153-2155.

97. Kim KA, Park PW, Hong SJ, Park JY. The effect of CYP2C19 polymorphism on the pharmacokinetics and pharmacodynamics of clopidogrel: a possible mechanism for clopidogrel resistance. Clin Pharmacol Ther. 2008;84:236-242.

98. Umemura K, Furuta T, Kondo K. The common gene variants of CYP2C19 affect pharmacokinetics and pharmacodynamics in an active metabolite of clopidogrel in healthy subjects. J Thromb Haemost. 2008;6:1439-1441.

99. Shuldiner AR, O'Connell JR, Bliden KP, et al. Association of cytochrome P450 2C19 genotype with the antiplatelet effect and clinical efficacy of clopidogrel therapy. JAMA. 2009;302:849-857.

100. Frere C, Cuisset T, Morange PE, et al. Effect of cytochrome P450 polymorphisms on platelet reactivity after treatment with clopidogrel in acute coronary syndrome. Am J Cardiol. 2008;101:1088-1093.

101. Geisler T, Schaeffeler E, Dippon J, et al. CYP2C19 and nongenetic factors predict poor responsiveness to clopidogrel loading dose after coronary stent implantation. Pharmacogenomics. 2008;9: 1251-1259.

102. Gladding P, Webster M, Zeng I, et al. The pharmacogenetics and pharmacodynamics of clopidogrel response: an analysis from the PRINC (Plavix Response in Coronary Intervention) trial. JACC Cardiovasc Interv. 2008;1:620-627.

103. Jinnai T, Horiuchi H, Makiyama T, et al. Impact of CYP2C19 polymorphisms on the antiplatelet effect of clopidogrel in an actual clinical setting in Japan. Circ J. 2009;73:1498-1503.

104. Sofi F, Giusti B, Gori AM, et al. Cytochrome P450 2C19 polymorphism and cardiovascular recurrences in patients under clopidogrel treatment: a meta-analysis. J Thromb Haemost. 2009;7(Suppl 2):105.

105. Bonello L, Camoin-Jau L, Armero S, et al. Tailored clopidogrel loading dose according to platelet reactivity monitoring to prevent acute and subacute stent thrombosis. Am J Cardiol. 2009;103:5-10.

106. Bonello L, Camoin-Jau L, Arques S, et al. Adjusted clopidogrel loading doses according to vasodilator-stimulated phosphoprotein phosphorylation index decrease rate of major adverse cardiovascular events in patients with clopidogrel resistance: a multicenter randomized prospective study. J Am Coll Cardiol. 2008;51:1404-1411.

107. Bonello L, Palot-Bonello N, Armero S, Camoin-Jau L, Paganelli F. Impact of loading dose adjustment on platelet reactivity in homozygotes of the 2C19 2 loss-of-function polymorphism. Int J Cardiol. 2009 Aug 25; doi:10.1016/j.ijcard.2009.07.033.

108. Jakubowski JA, Winters KJ, Naganuma H, Wallentin L. Prasugrel: a novel thienopyridine antiplatelet agent. A review of preclinical and clinical studies and the mechanistic basis for its distinct antiplatelet profile. Cardiovasc Drug Rev. 2007;25:357-374.

109. Rehmel JL, Eckstein JA, Farid NA, et al. Interactions of two major metabolites of prasugrel, a thienopyridine antiplatelet agent, with the cytochromes P450. Drug Metab Dispos. 2006;34:600-607. 
110. Mega JL, Close SL, Wiviott SD, et al. Cytochrome P450 genetic polymorphisms and the response to prasugrel: relationship to pharmacokinetic, pharmacodynamic, and clinical outcomes. Circulation. 2009;119:2553-2560.

111. Gori AM, Marcucci R, Paniccia R, et al. Thrombotic events in high risk patients are predicted by evaluating different pathways of platelet function. Thromb Haemost. 2008;100:1136-1145.
112. Paniccia R, Antonucci E, Maggini N, et al. Assessment of platelet function on whole blood by multiple electrode aggregometry in high risk patients with coronary artery disease receiving antiplatelet therapy. Am J Clin Pathol. 2009;131:834-842.

\section{Publish your work in this journal}

Pharmacogenomics and Personalized Medicine is an international, peerreviewed, open access journal characterizing the influence of genotype on pharmacology leading to the development of personalized treatment programs and individualized drug selection for improved safety, efficacy and sustainability. This journal is indexed on the American Chemical
Society's Chemical Abstracts Service (CAS). The manuscript management system is completely online and includes a very quick and fair peer-review system, which is all easy to use. Visit http://www.dovepress. com/testimonials.php to read real quotes from published authors.

Submit your manuscript here: http://www.dovepress.com/pharmacogenomics-and-personalized-medicine-journal 